\title{
Consensus Scientific Statement on Advisory Working Guidelines and Recommendations for the Female Population in COVID-19 Era by WINCARS
}

\author{
Shibba Takkar ${ }^{1}$ Maddury Jyotsna ${ }^{2}$ Prerna Goyal ${ }^{3} \quad$ Anurag Chaudhary ${ }^{4}$ Sujatha Vipperla ${ }^{5}$ \\ Yellapragada Hemalatha ${ }^{6}$ Vandana Midha ${ }^{7}$ Mary John ${ }^{8} \quad$ Amrutha Kakollu $^{9}$ Pooja Tandon ${ }^{10}$ \\ Suman Puri ${ }^{11}$ Hari Anupama ${ }^{12}$ Gagan Priya ${ }^{13}$ Benzeeta Pinto ${ }^{14}$ Vinitha P. Reddy ${ }^{15}$ \\ Monica M. Irukulla ${ }^{16}$ Aastha Takkar ${ }^{17}$ Mohanjeet Kaur ${ }^{18}$ Somdatta Karak ${ }^{19}$ Radha Vegesna ${ }^{20}$ \\ Deependir K. Chhina ${ }^{21}$ Poonam M. Kapoor ${ }^{22}$ Saroja Adapa ${ }^{23}$
}

\footnotetext{
${ }^{1}$ Department of Cardiology, Hero DMC Heart Institute Dayanand

Medical College, Ludhiana, Punjab, India

2Department of Cardiology, Nizam's Institute of Medical Sciences, Punjagutta, Hyderabad, India

${ }^{3}$ Department of Medicine, RG Stone and Super Specialty Hospital, Ludhiana, India

${ }^{4}$ Department of Community Medicine, Dayanand Medical College and Hospital, Ludhiana, Punjab, India

${ }^{5}$ Department of Cardiology, Indus Hospitals, Visakhapatnam, India

6 Department of Cardiology, Nizam's Institute of Medical Sciences, Punjagutta, Hyderabad, India

${ }^{7}$ Department of Medicine, Dayanand Medical College and Hospital, Ludhiana, India

${ }^{8}$ Department of Internal Medicine, Shree Raghunath Hospital, Ludhiana, India

${ }^{9}$ Department of Gynaecology and Obstetrics, Amrutha Clinic, Krishna Institute of Medical Sciences, India

10 Department of Obstetrics and Gynaecology, Dayanand Medical College and Hospital, Ludhiana, Punjab, India

${ }^{11}$ Dayanand Medical College and Hospital, Ludhiana, Punjab, India

12Department of Gynaecology and Obstetrics, Malla Reddy Medical College for Women, Hyderabad, India

${ }^{13}$ Department of Endocrinology, Fortis Hospital and Ivy Hospital,

Mohali, Punjab, India

${ }^{14}$ Department of Clinical Immunology and Rheumatology, St John's Medical College Hospital, Bengaluru, India
}

Ind J Car Dis Wom 2020;5:175-194

\section{Background}

We are presently facing the rapid progression and uncontrolled spread of the COVID-19 pandemic, with uncertainties in its management. There are national and international guidelines in general for the diagnosis and management of COVID and precautions needed for non-COVID patients. There is an apparent gender disparity in mortality due to COVID 19, which is less in women than in men. However, many diseases are specific to (like pregnancy-related complications and ovarian carcinoma ) or more frequent (many rheumatological diseases and mitral stenosis) in females, and have hardly been discussed in the context of the COVID pandemic. Moreover, recommendations are not available for our population. We, from the Women in Cardiology and
Address for correspondence Maddury Jyotsna, MD DM FACC FESC FICC, Nizam's Institute of Medical Sciences, Punjagutta, Hyderabad, Telangana, 500082, India (e-mail: janaswamyjyotsna@gmail.com).

15Department of Radiation Oncology, AIG Gachibowli, Hyderabad, India

16Department of Radiation Oncology, Nizam's Institute of Medical Sciences, Hyderabad, India

${ }^{17}$ Department of Neurology, Post Graduate Institute of Medical Education and Research, Chandigarh, India

${ }^{18}$ Department of Internal Medicine, Shree Raghunath Hospital, Ludhiana, India

${ }^{19}$ Department of Cellular and Microbiology, Science Molecular Biology and Public Outreach Officer, Council of Scientific and Industrial Research-Centre for Cellular and Molecular Biology, Hyderabad, India

${ }^{20}$ Department of Cellular and Microbiology, Centre for Cellular and Molecular Biology, Uppal, Hyderabad, India

${ }^{21}$ Department of Microbiology, Microbiology Department, Dayanand Medical College and Hospital, Ludhiana, India

22Department of Cardiac Anaesthesiology, Cardio Thoracic Centre, All India Institute Of Medical Sciences, New Delhi, India

${ }^{23}$ Department of Obstetrics and Gynaecology, Government Medical College, Nizamabad, India

Related Sciences (WINCARS) association, prepared a consensus scientific statement for the female population in this COVID-19 era.

\section{Aim}

Two aims of the studies are as follows:

1. To assemble the evidence for the management of different diseases pertinent to the female population in this COVID-19 era and formulate advisory guidelines and recommendations for medical fraternity and patients.

2. To highlight the issues, specific to female health care workers that require attention and formulate advisory recommendations.
DOI https://doi.org/ $10.1055 / \mathrm{s}-0040-1718607$
(C)2020 Women in Cardiology and Related Sciences
License terms

() (1) $\Theta \circledast$ 


\section{Methods}

For the very first time, the present document aims to collect, analyze, and interpret the available data so far on severe acute respiratory syndrome-coronavirus-2 (SARS-CoV-2) in relevance to the female gender via an expert group of medical specialists. Besides the variability across the globe in preventing, reporting, diagnosing, and management strategies, the obstacles for a comprehensive assessment include the availability of only small, single centered, or retrospective data. Moreover, rapid evolution and frequent change of scientific information, as we learn more about the disease and its complexities, add to the limitations.

To circumvent these shortcomings, the Delphi technique was deployed for a consensus-based statement., ${ }^{1,2}$ In this technique, a cluster of experts or individuals conversant on the subject are included. A task force committee constituted by 23 expert doctors (-Appendix 1; available online only) from the different departments were included. As this technique is applicable for the present article, it finds maximal utility in areas of limited or conflicting evidence where committee members may be geologically dispersed (from all over India), and anonymity is maintained to control for dominant individuals. The present document utilized the Delphi technique, and data collection was done from expert group members widespread across the nation.

Twenty-three members of the task force committee are from different places in India and also from different departments who took care of women patients from the onset of this pandemic. These expert doctors were requested to write the review articles with the latest literature, their personal experiences and recommendations, available in this COVID-19 era for both COVID-19 positive and negative female patients. The task force committee included gynecologists, obstetricians, rheumatologists, neurologists, internists, cardiologists, pulmonologists, preventive medicine specialists, endocrinologists, oncologists, microbiologists, and basic scientists.

Web-based brainstorming discussions were conducted with all experts, taking each disease separately. After scientific statements are prepared with a thorough literature search, views of another set of experts (names are mentioned in acknowledgments, -Appendix 2 [available online only]) were taken in the questionnaire form. We mentioned the questionnaire and concordance rate of the expert's opinion as a percentage to the particular statement (mentioned as the table in -Appendix 3; available online only). The scientific statements have been enlisted among various medical disciplines affecting women the most via the SARS-CoV-2 virus. Authors have suggested the pertinent class of recommendation in the text subject to change via an ever-growing and evolving data on COVID-19. Audio of consensus scientific statement is available online (-Audio 1).

\section{Audio 1}

Audio of consensus scientific statement. Online content including audio sequences viewable at: https:// www.thieme-connect.com/products/ejournals/ html/10.1055/s-0040-1718607.

\section{Purpose and Clinical Application of the Scientific Statements}

These scientific statements are prepared with sufficient knowledge of the subspecialties to ensure that women patients will be managed appropriately, in time, and effectively. The expertise of these sub-specialized medical branches domains is covered elsewhere and not included in this document.

\section{Cardiology}

Cardiovascular Disease and COVID-19: Issues in Women Though American College of Cardiology/American Heart Association (ACC/AHA) and European Society of Cardiology (ESC) medical bodies released recommendations and statements on acute coronary syndromes (ACS) presentation in COVID-19 patients, we discussed specific problems related to women with COVID in India ( - Table $\mathbf{1}$ ).

According to $\mathrm{Wu}$ et $\mathrm{al}^{3}{ }^{3}$ in their large study of 18,465 laboratory-confirmed cases, the predictors of mortality were comorbidities like hypertension, diabetes, and chronic kidney diseases. Furthermore, the association between diabetes and the risk of death from COVID-19 was prominent in women (hazard ratio $[\mathrm{HR}]=1.69,95 \%$ confidence interval $[\mathrm{CI}]: 1.27-2.25)$ than in men $(\mathrm{HR}=1.16,95 \%$ CI: 0.91-1.46; P for interaction $=0.036$ ).

All the recent studies ${ }^{4-7}$ of hospitalized patients with COVID-19 infection found that apart from comorbidities, an additional determinant of mortality was myocardial injury diagnosed by an elevated troponin, incidence of which was no different in men and women.

Atypical clinical symptoms, along with late presentation, cause delays in diagnosis and management in women, which have been more pronounced during this pandemic according to published literature. ${ }^{8-13}$

Rapid antigen testing should be done before primary angioplasty following an ST elevation myocardial infarction (STEMI), according to CSI (Cardiological Society of India)

Table 1 COVID-19 in women with CVD

\begin{tabular}{|l|l|}
\hline $\begin{array}{l}\text { Scientific statements for CVD in females } \\
\text { with COVID-19 }\end{array}$ & References \\
\hline $\begin{array}{l}\text { The association between diabetes and risk of } \\
\text { death from COVID-19 is more in women than men }\end{array}$ & 3 \\
\hline $\begin{array}{l}\text { Incidence of myocardial injury is not different } \\
\text { between men and women, but is associated with } \\
\text { increased mortality upon COVID }\end{array}$ & $4-7$ \\
\hline $\begin{array}{l}\text { Diagnosis of acute coronary syndromes in the } \\
\text { setting of COVID-19 is further confounded in } \\
\text { women and is fraught with delays in presentation } \\
\text { resulting in dilemmas in management (more so } \\
\text { in women) }\end{array}$ & $8-13$ \\
\hline $\begin{array}{l}\text { Point of care antigen testing should be done } \\
\text { before primary PCI in STEMI patients }\end{array}$ & 14 \\
\hline $\begin{array}{l}\text { A strategy of fibrinolysis in STEMI and COVID-19 in } \\
\text { India is an acceptable alternative, especially in } \\
\text { women as nonobstructive coronary artery disease } \\
\text { incidence is high }\end{array}$ & $8,14-16$ \\
\hline
\end{tabular}

Abbreviations: COVID-19, novel coronavirus disease 2019; CVD, cardiovascular disease; $\mathrm{PCl}$, percutaneous coronary intervention. 
document on acute myocardial infraction (AMI) care during COVID-19. The document also insists that proper protection to the operator and staff in the form of appropriate personal protection equipment (PPE) should be available whenever primary percutaneous coronary intervention (PCI) is planned for STEMI. ${ }^{14}$ In India, fibrinolysis is the dominant strategy used in patients with STEMI in view of logistic considerations. ${ }^{15}$ European guidelines recommend primary PCI even in patients with COVID-19 infection. ${ }^{16}$ With the available literature, fibrinolysis for STEMI can be graded as classIIB, level-C recommendation.

\section{Venous Thromboembolic Events in COVID-19-Are Women Different?}

As International Society on Thrombosis and Haemostasis $(\text { ISTH })^{17} / \mathrm{NATF} /$ European Society for Vascular Medicine (ESVM)/Intrauterine Adhesions (IUA) consensus paper and multiple medical bodies published on the prothrombotic state of COVID-19, predisposing these patients' to venous thromboembolic events (VTE). In this study, we mentioned the prophylaxis and management specifically for all ages of females with COVID-19 ( - Table 2).

Barring one study by Cui et $\mathrm{al}^{18}$ in which a female predilection for VTE was found to the tune of $64 \%$ in women versus $46 \%$ men, almost all the other studies have shown higher predilection of VTE events in the male population. Spiezia et $\mathrm{al}^{19}$ and Ranucci et $\mathrm{al}^{20}$ reported 91 and $94 \%$ of patients having VTE in males, respectively, whereas most of the other studies reported 60 to $80 \%$ of their patients with COVID-19 having VTE in men. ${ }^{21} \mathrm{~A}$ recent study from Italy ${ }^{22}$ published in midJuly, persistent gender gap in the occurrence of VTE events was further emphasized. In answer to our questionnaire, there was discordance with only $34.8 \%$ of experts opining less VTE

Table 2 VTE in females with COVID-19

\begin{tabular}{|l|l|}
\hline $\begin{array}{l}\text { Scientific statements for VTE in females } \\
\text { with COVID-19 }\end{array}$ & References \\
\hline $\begin{array}{l}\text { Less female predilection of VTE in } \\
\text { COVID-19 pandemic is observed }\end{array}$ & $18-22$ \\
\hline $\begin{array}{l}\text { Combined oral contraceptives and estrogen } \\
\text { replacement therapy should be discouraged in } \\
\text { COVID-19-positive women to prevent VTE }\end{array}$ & $23-26$ \\
\hline $\begin{array}{l}\text { Thromboprophylaxis in standard doses is must } \\
\text { in all COVID-19-positive hospitalized women } \\
\text { (with low bleeding risk, to continue in menstrual } \\
\text { period) }\end{array}$ & $17,27,28$ \\
\hline $\begin{array}{l}\text { Thromboprophylaxis in intensified doses is } \\
\text { recommended in COVID-19-positive hospital- } \\
\text { ized women with deranged hematological and } \\
\text { clinical parameters of disease severity (with low } \\
\text { bleeding risk, to continue in menstrual period) }\end{array}$ & $29-34$ \\
\hline $\begin{array}{l}\text { COVID-19-positive women on home quarantine } \\
\text { should receive thromboprophylaxis only when } \\
\text { at high risk for VTE (with low bleeding risk) }\end{array}$ & 1,28 \\
\hline $\begin{array}{l}\text { Extended thromboprophylaxis post-discharge } \\
\text { is recommended in COVID-19-positive women } \\
\text { with high VTE risk and low bleeding risk }\end{array}$ & $1,27,29,36-38$ \\
\hline
\end{tabular}

Abbreviations: COVID-19, novel coronavirus disease 2019; VTE, venous thromboembolism. predilection in COVID positive women. However, there is enough evidence to suggest otherwise. This also explains the imperative need to publish the assimilated data and put forth the differences in VTE predilection in COVID positive women.

With ongoing research on the effects of SARS-CoV-2 on coagulation systems, the issues of aggravated risk of VTEs associated with combined oral contraceptives (COC's) and other estrogen therapies as well as pregnancy-associated risks needs to be resolved. COC use is associated with a 2- to 6-fold increase in risk for VTEs. ${ }^{23}$ Similar data exist for oral hormone replacement therapy (HRT) in menopausal women ${ }^{24}$ and oral estrogen therapy in male-to-female transgender patients. In pregnancy, the risk of VTEs increases four to five folds. ${ }^{25}$ The hypercoagulable state in the pathophysiology, and the duration for which thrombogenic milieu might persist after discontinuing therapy remains to be understood. However, on the basis of usual preexistent recommendations to discontinue estrogen-containing preparations 2 weeks before planned activities that may increase thrombogenesis, such as surgery or long flights, it might be considered to discourage initiation and hold these drugs in women who develop SARS-CoV-2 infection. ${ }^{26}$ With the available literature information, the avoidance of combination therapy of $\mathrm{COC}$ and estrogen can be graded as class-II, level-B recommendation.

Thromboprophylaxis for VTE in COVID-19-positive hospitalized women remains essentially similar to males. Issues may arise in women with menorrhagia;secondary to dysfunctional uterine bleeding (DUB), fibroids, adnexal malignancies, and masses, hypothyroidism, women on anticoagulation, etc., where bleeding risks are to be considered. The guidelines can be similar in either sex, with attention to bleeding risk scenarios and menstrual physiology specific to women. Given COVID-19's thrombogenic potential, it is suggested that thromboprophylaxis should be continued in standard doses in a normal menstrual period with monitoring for menorrhagia. One of the first published guidelines Chinese Medical Doctor Association (CMDA), ${ }^{27}$ the ISTH ${ }^{28}$ and thrombosis-UK ${ }^{17}$ recommendations advocated a standard approach to in-hospital thromboprophylaxis of COVID-19 patients, with a standard dose following a validated clinical score. ${ }^{17,27}$ With the available literature information, the thromboprophylaxis in COVID-19 patients can be graded as class-I, level-C recommendation.

Intensified/therapeutic doses of thromboprophylaxis may be considered in sicker COVID-19-positive women with clinically severe disease and raised markers of disease severity (e.g., D-dimer, ferritin, and fibrinogen). Bleeding risks due to menorrhagia need to be considered, and it is suggested to continue intensified thromboprophylaxis during a normal menstrual cycle. Chinese Consensus Statement (CCS), ${ }_{,}^{29}$ the joint guidelines of the French Working Group on Perioperative Hemostasis (GIHP) and the French Study Group on Thrombosis and Haemostasis (GFHT), ${ }^{30}$ the NIPHN, ${ }^{31}$ the Society of Thrombosis and Haemostasis (GTH), ${ }^{32}$ the Spanish Society of Cardiology (SSC), ${ }^{33}$ and the Swiss Society of Haematology ${ }^{34}$ recommended intensified doses of heparin for thromboprophylaxis based on the severity of the clinical or biological disease. Four guidelines suggested using 
full-dose anticoagulation according to inflammation-related biological parameters in all patients on oxygen ${ }^{30,33}$ therapy or in patients with an increase of D-dimers while on prophylaxis. ${ }^{32,34}$ With the available literature information, the intensified doses of thromboprophylaxis in COVID-19 patients as can be graded as class-I, level-C recommendation.

In women with mild COVID-19 who have been quarantined, the role of pharmacological prophylaxis is yet uncertain (just as in men); hence these patients can be advised to remain mobile at home. The pharmacological prophylaxis in these patients could be reserved for women at high risk of developing VTE (and low bleeding risk). For instance, in those who have reduced mobility, a previous history of thromboembolic event, or in those who have active ongoing malignancy. Standard-dose thromboprophylaxis is recommended in outpatient COVID-19 patients with multiple VTE risk factors by the Society for Thrombosis and Haemostasis (SISET) and the GTH guidelines. The ISTH ${ }^{17} / \mathrm{NATF} / \mathrm{ESVM} / \mathrm{IUA}$ consensus paper also recommends considering thromboprophylaxis on an individual case basis for patients with an elevated risk of VTE without high bleeding risk ( - Table 1). Based on available literature information, the thromboprophylaxis in home-quarantined female COVID-19 patients can be graded as class-II, level-C recommendation.

Investigation, management including type of heparin during acute stage, and novel oral anticoagulant (NOAC) subsequently and method of follow-up are similar to both men and women.

A daily dosing regime of low molecular weight heparin (LMWH) has an advantage over unfractionated heparin with twice-daily doses in COVID-19 by reducing the use of PPE and exposing the COVID-19 health care workers. For in hospital prophylaxis, the World Health Organization recommends daily LMWH or twice daily subcutaneous unfractionated heparin. Hence just as in males, LMWH may be preferred over unfractionated heparin (UFH) in COVID-19-positive females. ${ }^{35}$ This is graded as class-II, level-C recommendation with available information.

COVID-19-positive women with persistent high VTE risk and low bleeding risk are suggested to continue an extended thromboprophylaxis regime up to 45 days. ASH guidelines, ${ }^{36}$ the CMDA, ${ }^{27}$ the $\mathrm{CCS}^{29}$ recommendations, the $\mathrm{GTH}^{37}$ the Italian (SISET), ${ }^{38}$ and the ISTH/NATF/ESVM/ IUA ${ }^{1}$ position paper recommend extended prophylaxis postdischarge up to 45 days in case of a high risk of VTE with low bleeding risk. ${ }^{38}$ This is considered as class-II, level-C recommendation with available information.

Catheter-based therapies should be reserved only when systemic fibrinolysis may not be feasible in the settings where infection control is well equipped, appropriate, and equivalent. Bedside extra corporeal membrane oxygenator (ECMO) might be considered in COVID-19-positive patients rather than the utilization of interventional modalities needing cardiac catheterization laboratories or operating rooms. ${ }^{35}$ This is graded as class-II, level-C recommendation with available information.

An elevated D-dimer level, a marker of severity of COVID-19, might not routinely indicate an underlying venous thromboembolic process. ${ }^{39} \mathrm{~A}$ VTE event should be suspected in a woman of COVID-19 when she developed typical deep vein thrombosis (DVT) symptoms, hypoxemia was out of proportion to the underlying respiratory pathology or development of acute unexplained right ventricle (RV) dysfunction. The diagnostic challenges in a patient with COVID-19 for VTE are the risk of transmitting the infection to other patients or health care workers due to an unstable patient and prone position of the patient with severe acute respiratory distress syndrome (ARDS) limiting the imaging studies. Echocardiography might be considered in these patients with COVID-19 for evaluation of worsening RV dysfunction and diagnosis of right ventricular clots/clots in transit. ${ }^{40}$ Computed tomography (CT) pulmonary angiography may be omitted in very sick COVID-19 patients due to minimal anticipated therapeutic benefits and increased exposure of health care worker. Routine imaging modalities for VTE evaluation are not advisable; this is graded as class II, level-C recommendation and available information.

In patients without COVID-19 and acute VTE, outpatient management, or an early discharge should be considered. ${ }^{41}$ This is graded as Class I, level-C recommendation with available information. Telemedicine could be the preferred methodology of follow-up (class I, level C). Regarding pharmacotherapy, these patients could be maintained on NOACs or LMWH to avoid recurrent contact with the health care workers for maintenance of international normalized ratio's (INR's) inpatient receiving vitamin-K antagonists. This is graded as class-I, level-C recommendation with available information. In patients already receiving vitamin-K antagonists, extending INR testing in intervals could be suggested if prior INR's have been stable. Home-based INR's check or drive through INR testing should be encouraged, though switching to NOACs or LMWH would be the clinically appropriate strategy wherever feasible. The NOACS used are dabigatran or rivaroxaban. There are a few studies with oral antithrombolytic enzyme (nattokinase) as anticoagulant.

\section{COVID-19 and Cardioobstetric Risk Indicators}

Recently preventive medicine is paying much importance to the cardioobstetrics risk stratification for the future onset of cardiovascular disease (CVD) in pregnant females. As there is limited information about the effect of COVID-19 on pregnancy, which may influence the mother's long-term cardiac health, through these scientific statements, we are trying to fill the knowledge gaps ( - Table 3 ).

Nonsteroidal anti-inflammatory drugs (NSAIDs), such as ibuprofen, have been found to cause pulmonary disease progression in COVID-19 infection in a few anecdotal reports by French authorities. Indian Council of Medical Research (ICMR), in an official statement on 27 March 2020, issued an advisory for avoiding NSAIDs for patients with diabetes, hypertension, and heart diseases due to increased risk of SARS-CoV-2 progression and advised paracetamol as a safer alternative. However, later on, World Health Organization (WHO) and Spanish Ministry of Health and European Medicines Agency in their reports, stated that there is no scientific evidence that ibuprofen (or other NSAIDs) could worsen SARS-CoV-2 infection. ${ }^{42}$ Given this uncertainty, 
Table 3 Cardio-obstetric risk indicators in females with COVID-19

\begin{tabular}{|l|l|}
\hline $\begin{array}{l}\text { Scientific statements for cardioobstetric risk } \\
\text { indicators in females with COVID-19 }\end{array}$ & References \\
\hline $\begin{array}{l}\text { Low dose aspirin as prophylaxis for placental } \\
\text { complications including pre-eclampsia and fetal } \\
\text { growth restriction should not be withdrawn in } \\
\text { high-risk COVID-19 pregnant women in fear of the } \\
\text { increased risk of SRAS-CoV-2 progression }\end{array}$ & 42 \\
\hline $\begin{array}{l}\text { COVID-19 infection in pregnant women does not } \\
\text { lead to a greater incidence of obstetric complica- } \\
\text { tions like preterm birth, pre-eclampsia }\end{array}$ & 43 \\
\hline $\begin{array}{l}\text { Near term pregnant or postpartum women } \\
\text { with COVID-19 pneumonia, developing high } \\
\text { respiratory rate or dyspnea should be evaluated } \\
\text { for new-onset cardiomyopathy with the help of } \\
\text { handheld point-of-care echocardiograms }\end{array}$ & \\
\hline $\begin{array}{l}\text { Pregnant women with severe COVID-19 infection } \\
\text { can develop a PE like syndrome that might be } \\
\text { distinguished from actual PE by additional estima- } \\
\text { tion of biomarkers }\end{array}$ & 46 \\
\hline $\begin{array}{l}\text { All pregnant women admitted with COVID-19 } \\
\text { infection should be considered for antenatal } \\
\text { VTE prophylaxis while those with mild } \\
\text { COVID-19 infection and on home isolation should } \\
\text { undergo VTE risk assessment to decide about VTE } \\
\text { prophylaxis }\end{array}$ & \\
\hline
\end{tabular}

Abbreviations: COVID-19, novel coronavirus disease 2019; SRAS-CoV-2, severe acute respiratory syndrome-coronavirus-2; VTE, venous thromboembolism.

aspirin, because of greater beneficial effects than low-level data of potential harm, should not be withheld as a prophylactic measure for preeclampsia in high-risk pregnant females, especially in the initial few months. Near-term, patients should be assessed on a case-by-case basis for the risk-benefit ratio. The statement on continuation of aspirin prophylaxis in preeclampsia is graded as Class II, level C recommendation with available information.

Limited case series and small cohort studies report increased incidence of preterm births and preeclampsia in COVID-19 infected pregnant females with no effects on miscarriage rate, stillbirths, and teratogenicity (class II, level CLE [cutaneous lupus erythematous]). Most preterm births are reported to be iatrogenic either due to the severity of illness or maternal/fetal safety. ${ }^{43}$ Diagnosis of preeclampsia in severe SARS-CoV-2 infection is challenging due to overlapping clinical and laboratory profile. Thus in the absence of definitive diagnostic testing like placental histopathology, the Doppler assessment that is an actual incidence of preeclampsia in severe infection needs reconsideration.

New-onset cardiomyopathy has been demonstrated in 33\% of nonpregnant COVID-19 patients who required intensive care. ${ }^{44}$ An increased incidence of stress/takotsubo cardiomyopathy (TCM) was found in a cohort study of 1,914 patients who presented with acute coronary syndrome during the COVID-19 pandemic compared with the prepandemic period. ${ }^{45}$ However, the effects of SARS-CoV-2 on myocardial function or incidence of peripartum cardiomyopathy (PPCM) in pregnant females remain mostly unknown to date due to diagnostic challenges. Pregnant women with confirmed or suspected COVID-19 infection, presenting with respiratory distress, should be evaluated for new onset of systolic dysfunction by cardiac enzymes and echocardiogram (class I, level C-LD).

Overlapping clinical and laboratory parameters of preeclampsia/HELLP and COVID-19 infection like liver injury, thrombocytopenia, and coagulopathy may confer diagnostic challenges to clinicians. Presenting fever symptoms in COVID-19 infection or predominant finding of high blood pressure (BP) in pulmonary embolism (PE) may help differentiate between both to some extent on clinical grounds. The Doppler assessment (uterine artery pulsatility index) and estimation of angiogenic factors (soluble FMS-like tyrosine kinase-1/placental growth factor and lactate dehydrogenase) are few of the diagnostic measures to distinguish severe COVID-19 infection from true PE. Therefore, diagnosis of preeclampsia ${ }^{46}$ in COVID-19 needs a careful approach and should interpreted in all aspects.

American College of Obstetricians and Gynecologists (ACOG) advises antenatal thromboprophylaxis in all suspected/confirmed COVID-19 pregnant patients, particularly in severe/critical disease. ${ }^{47}$ Royal College of Obstetricians and Gynecologists (RCOG) recommends that pregnant women with mild infection and home isolation undergo clinical VTE risk assessment via telehealth or office visits, and thromboprophylaxis should be considered based on their risk score. ${ }^{48}$ There is no such scientific statement by Indian academic bodies for the mildly symptomatic pregnant subgroup (class II, level B). As pregnancy and COVID-19 together may pose a distinctive increased thrombotic risk, whether patients with mild infections should be risk assessed or empirically started on prophylaxis remains questionable.

\section{Drug-Drug and Drug-Disease Interactions in Females with COVID-19}

Treatment protocols of COVID-19 are still evolving. Here, we mentioned the interactions between COVID-19 drugs and drugs taken by female patients for their gender-specific diseases (-Table 4).

Though the revised protocols of ICMR allow hydroxychloroquine (HCQ) to be prescribed to patients in the early course of the disease, it has also advised against the use of severe disease. ${ }^{49}$ HCQ administered to nursing women is excreted in human milk. ${ }^{50}$ It is known that infants are susceptible to the toxic effects of 4-aminoquinolines. No need to discontinue this drug during pregnancy. ${ }^{51}$ If Systemic lupus erythematosus (SLE) women on this drug become pregnant; it has not shown any adverse effects on the fetus even though the cord blood sample has the same concentration of the drug of the mother serum concentration.

Anticoagulants are indicated in moderate and severe degrees of COVID disease, as this is a procoagulant status. Any patient who is admitted to the hospital during the COVID19 pandemic and is taking warfarin (or any other coumarin anticoagulant, e.g., phenindione and acenocoumarol) should be considered for switching to a direct oral anticoagulant (DOAC) to avoid the need for ongoing monitoring in hospital and community-based clinics. But this conversion should 
not be done in a few clinical condition like situations when patients should not be switched from warfarin. ${ }^{52,53}$

According to ICMR revised treatment protocol, tocilizumab (off label) may be considered in patients with moderate disease with progressively increasing oxygen requirements and mechanically ventilated patients were not improving despite steroids. ${ }^{54}$ Tocilizumab is a novel monoclonal antibody that competitively inhibits the binding of interleukin-6 (IL-6) to its receptor (IL-6R). Hoeltzenbein et a ${ }^{54}$ and Saito et al demonstrated that no indication for a substantially increased malformation risk was observed with tocilizumab usage during pregnancy. ${ }^{55,56}$ Monoclonal antibodies are actively transported across the placenta during the third trimester. They may affect immune response in the in utero exposed infant as the immunoglobulin (Ig)-G isotype's endogenous immunoglobulins are excreted into human milk. It is advisable to discontinue the drug during lactation.

According to ICMR's latest guideline for COVID-19 treatment, remdesivir (under Emergency Use Authorization) may be considered in patients with moderate disease (those on oxygen). Remdesvir is considered an investigational drug. ${ }^{57}$ In vitro, remdesivir is an inhibitor of CYP3A4, OATP1B1, OATP1B3, BSEP, MRP4, and NTCP. Inhibitors of MRP4 include nonsteroidal inflammatory drugs, phosphodiesterase inhibitors, cardiovascular drugs, and flavonoids, among others. ${ }^{57}$ Phosphodiesterase inhibitors, Which are used in primary pulmonary hypertension, common in females have drug-drug interaction (DDI) with remdesivir (level II, evidence C).

According to ICMR's latest guideline for COVID-19 treatment, favipiravir is considered an investigational drug. ${ }^{58}$ The favipiravir drug undergoes metabolism in the liver mainly by aldehyde oxidase (AO), and partially by

Table 4 Drug and drug-disease interactions in females with COVID-19

\begin{tabular}{|l|l|}
\hline $\begin{array}{l}\text { Scientific statements for drug-drug and } \\
\text { drug disease interactions in females with } \\
\text { COVID-19 }\end{array}$ & References \\
\hline $\begin{array}{l}\text { Caution be exercised when administering hydrox- } \\
\text { ychloroquine to breastfeeding women }\end{array}$ & $49-51$ \\
\hline $\begin{array}{l}\text { To avoid strict monitoring in COVID-19 patients } \\
\text { already on warfarin, conversion of warfarin to } \\
\text { direct oral anticoagulant is advised except in preg- } \\
\text { nant or breastfeeding women or mechanical heart } \\
\text { valves or severe mitral stenosis or triple positive } \\
\text { anti-phospholipid syndrome }\end{array}$ & 52,53 \\
\hline $\begin{array}{l}\text { Tocilizumab may be given to COVID-19 pregnant } \\
\text { women if risk versus benefit favors drug usage, } \\
\text { but not lactating women. If it is essential for } \\
\text { lactating women, then better discontinue } \\
\text { breastfeeding }\end{array}$ & $54-56$ \\
\hline $\begin{array}{l}\text { Remdesvir and phosphodiesterase inhibitors, both } \\
\text { affect each other as both are MRP4 inhibitors }\end{array}$ & 57,58 \\
\hline $\begin{array}{l}\text { Monitoring for side effects of favipiravir is required } \\
\text { as the drug levels are increased in patients when } \\
\text { given along with estrogen receptor modulators }\end{array}$ & $58-60$ \\
\hline
\end{tabular}

Abbreviation: COVID-19, novel coronavirus disease 2019. xanthine oxidase, producing an inactive oxidative metabolite T-705M1 excreted by the kidneys. ${ }^{59}$ Selective estrogen receptor modulators (raloxifene, tamoxifen, and estradiol), which are used in treatment of breast cancer, osteoporosis, and postmenopausal symptoms are potent AO inhibitors (in vitro). However, the clinically relevant DDI based on AO inhibition has yet to be established, ${ }^{60}$ precaution is to be taken when favipiravir given along with selective estrogen receptor modulators (level II, evidence C).

\section{Internal Medicine}

\section{Scientific Statement on Clinical Spectrum in COVID-19}

There are extensive reviews based on the experience of several practitioners describing the typical clinical presentation of COVID 19 in the form of influenza-like illness in the literature. We therefore aim to concentrate on few of the other important clinical components which require special attention, and have not yet received much recognition, like the new onset of lung fibrosis as a consequence, predominant gastrointestinal involvement and role of androgen hormone in clinical symptomatology ( - Table 5 ).

Data from previous coronavirus infections, such as SARS and the Middle East respiratory syndrome (MARS), and emerging data from the COVID-19 pandemic suggest that there could be substantial fibrotic consequences following SARS-CoV-2 infection. Antifibrotic therapies ${ }^{61}$ that are available or in development could have value in preventing severe COVID-19 in patients with idiopathic pulmonary fibrosis (IPF). These drugs may be useful even in severe COVID-19 in patients without IPF ${ }^{62}$ and might have a role in preventing fibrosis after SARS-CoV-2 infection (class II, level C). As there are increasing reports of lung fibrosis secondary to SARS-CoV-2 infection, there is an urgent need for preventive therapies that alleviate the severity of COVID-19.

A systematic review and meta-analysis of data from 29 studies, including 6,064 patients with COVID-19, showed a pooled prevalence of $15 \%$ (95\% CI: $10-21$ ) for digestive symptoms $s^{63}$ most common being nausea or vomiting, diarrhea, and anorexia. Around $10 \%$ of patients presented with

Table 5 Clinical spectrum in COVID-19

\begin{tabular}{|l|l|}
\hline $\begin{array}{l}\text { Scientific statements on clinical } \\
\text { manifestations of COVID-19 }\end{array}$ & References \\
\hline $\begin{array}{l}\text { All COVID-19 patients with moderate to severe } \\
\text { lung involvement shall be closely followed and } \\
\text { evaluated for post COVID-19 pulmonary compli- } \\
\text { cations with follow-up pulmonary function tests } \\
\text { and CT chest to assess for new-onset pulmonary } \\
\text { fibrosis to target for timely antifibrotic therapies }\end{array}$ & 61,62 \\
\hline $\begin{array}{l}\text { Patients presenting with only GIT symptoms like } \\
\text { nausea, vomiting, diarrhea shall be evaluated } \\
\text { for COVID-19 infection even in the absence } \\
\text { of respiratory symptoms during the ongoing } \\
\text { COVID-19 pandemic }\end{array}$ & 63,64 \\
\hline $\begin{array}{l}\text { Males with an androgenic pattern are more sus- } \\
\text { ceptible to COVID-19 infection and that too with } \\
\text { higher severity }\end{array}$ & 65 \\
\hline
\end{tabular}

Abbreviations: COVID-19, CT, computed tomography; novel coronavirus disease 2019; GIT, gastrointestinal tract. 
gastrointestinal symptoms ${ }^{64}$ without respiratory features when infected with SARS-CoV-2. These patients' sunset is more likely to have a delayed diagnosis, owning to predominant gastrointestinal involvement only, which can lead to potential problems of mismanagement and can pose transmission to health care workers (class II, level A).

Recently scientists discovered that an enzyme called transmembrane protease serine 2 (TMPRSS2) helps virus entry inside the cells as it cleaves the SARS-CoV-2's spike protein, enabling it to bind to the angiotensin converting enzyme 2 (ACE2) receptor. The gene that encodes TMPRSS2 is activated when male hormones, particularly dihydrotestosterone, bind to the androgen receptor (a protein on the cells' surface, including hair cells and lung cells). The more male hormone, the more androgen receptor binding, and the more TMPRSS2 is present, and the easier it is for the virus to get in. This has been supported in a preliminary, non-peer-reviewed study that correlated the androgen levels of hundreds of people in the United Kingdom with COVID-19 severity. Higher androgen level (exemplified by baldness) was associated with susceptibility to and severity of COVID-19 in men $^{65}$ (but not women, who have much lower androgen levels in their blood; level II, evidence C).

\section{Management of COVID-19: Evidence and Experience}

ICMR and hospital-based management guidelines are available for all the grades of the COVID-19. Here, we mention the scientific statements pertaining to the controversial areas of treatment with steroids, Remdesvir, and Tocilizumab along with laboratory investigations (-Table 6).

Infection-mediated endothelial cell damage (expression of ACE2 in arterial and venous endothelium) leads to excessive thrombin production, inhibition of fibrinolysis, and activation of complement pathways, leading to thromboinflammation and deposition of microthrombi and microvascular dysfunction. ${ }^{66}$ Elevated/rising D-dimer levels associated with hypoxia is due to VTE or in situ thrombosis (level of evidence moderate for prophylactic and low for therapeutic).

The hyperinflammatory state in COVID-19 due to a dysregulated systemic inflammation leads to a cytokine release syndrome with an increase in inflammatory markers

Table 6 Management of COVID-19-controversies

\begin{tabular}{|l|l|}
\hline $\begin{array}{l}\text { Scientific statements for management of } \\
\text { COVID-19 }\end{array}$ & References \\
\hline $\begin{array}{l}\text { Elevated/rising D-dimer levels, along with worsen- } \\
\text { ing hypoxemia, may indicate ongoing thrombosis } \\
\text { and need to be treated with prophylactic or } \\
\text { therapeutic doses of anticoagulants }\end{array}$ & 66 \\
\hline $\begin{array}{l}\text { In patients hospitalized for COVID-19, with hypox- } \\
\text { emia, glucocorticoids are to be used (dexametha- } \\
\text { sone 6-mg IV or oral for } 10 \text { days/till discharge) }\end{array}$ & 67 \\
\hline $\begin{array}{l}\text { Consider the use of remdesivir for } 5 \text { days in } \\
\text { patients with moderate COVID-19 disease, not on } \\
\text { mechanical ventilation }\end{array}$ & 68 \\
\hline $\begin{array}{l}\text { Consider tocilizumab in the context of a clinical } \\
\text { trial }\end{array}$ & 68 \\
\hline
\end{tabular}

Abbreviations: COVID-19, novel coronavirus disease 2019; IV, intravenous.
(C-reactive protein [CRP], ferritin, IL-6, and lactate dehydrogenase [LDH]). Steroids are used as anti-inflammatory agents ${ }^{67}$ (level of evidence, moderate).

Remdesivir demonstrates the best results early in the disease in COVID-19 patients requiring only supplemental oxygen rather than those on mechanical ventilation. ${ }^{68}$ (level of evidence moderate).

Proinflammatory cytokines (IL-6) are released during the COVID-19 illness. Tocilizumab, an IL-6 blocker, was shown to reduce mortality in only one study in which there is no control $\operatorname{arm}^{68}$ (level of evidence, knowledge gap).

\section{Gynecology-Obstetrics}

Scientific Statements on the Gynecology Practice during COVID-19 Pandemic

AGOS (American Gynecological and Obstetrical Society) and the Federation of Obstetric and Gynecological Societies of India laid down the guidelines for gynecological practices in this COVID19 era. This scientific statement's main aim is an odoption of the standard gynecological practices for pre and postmenopausal bleedings to our local geographical area ( - Table 7 ).

Patients who present with abnormal uterine bleeding should be assessed initially regarding the severity of bleeding. If the bleeding is extremely severe, needing a blood transfusion, a temporary measure, like curettage, can be performed to arrest bleeding, and further management can be planned $^{69}$ (class IIa, level C-LD). Medical management with progesterone should be offered to patients with mild to moderate bleeding as a measure to delay surgery.

In women with postmenopausal bleeding, the risk of malignancy should be given utmost priority. However, patients can be triaged based on their risk factors and the thickness of endometrium on ultrasound. Women with a low risk of malignancy and a normal ultrasound endometrial thickness can be managed conservatively and need to be counseled to maintain follow-up ${ }^{70}$ (class IIa, level C-EO).

\section{Scientific Statements on Gynecological Endoscopic Surgery during COVID-19 Pandemic}

International societies, like British Society of Gynecological Endoscopy (BSGE), published guidelines for gynecological endoscopic surgery during COVID-19 pandemic. The following statements ( $\mathbf{- T a b l e ~} 8$ ) are for preoperative screening

Table 7 COVID-19 infections and gynecology practice

\begin{tabular}{|l|l|}
\hline $\begin{array}{l}\text { Scientific statements on } \\
\text { COVID-19 infections and gynecology } \\
\text { practice }\end{array}$ & References \\
\hline $\begin{array}{l}\text { Patients with heavy menstrual bleeding should } \\
\text { be managed medically when feasible unless } \\
\text { the patient presents with acute or intractable } \\
\text { bleeding causing anemia, and requiring blood } \\
\text { transfusion }\end{array}$ & 69 \\
\hline $\begin{array}{l}\text { Patients with postmenopausal bleeding and low } \\
\text { risk of malignancy with normal ultrasound can } \\
\text { be offered reassurance and advised to report } \\
\text { persistent or recurrent symptoms as the risk of } \\
\text { malignancy in these patients is relatively low }\end{array}$ & 70 \\
\hline
\end{tabular}

Abbreviation: COVID-19, novel coronavirus disease 2019. 
strategy before gynecologic endoscopic surgery for the safety of the operating team, surgical smoke generation during gynecologic endoscopy, and risk of transmission of infection and alternative treatments.

In addition to screening patients clinically for symptoms or contact with COVID-19, most studies have recommended using reverse transcriptase polymerase chain reaction (RT-PCR) for diagnosing COVID-19 infection, as it has a sensitivity between 70 and $85 \% .^{71}$ The likelihood of a false negative RT-PCR, which has been reported up to $15 \%$, should be borne in mind, and a CT of chest can be considered besides for efficient diagnosis as this has a direct impact on the operating team, anesthetic team, and entire theater staff (class IIA, level C-LD).

The presence of COVID-19 in the aerosol particles of evacuated smoke during laparoscopy has not been identified. However, it is surmised from the existing limited evidence of demonstrating viruses in the aerosol generated during endoscopic surgery. ${ }^{72}$

To minimize the leakage of aerosolized viral particles into the theater environment, measures need to be taken for closed-circuit smoke evacuation with commercial smoke evacuators or a wall suction. ${ }^{73}$ The main aim is to avoid concentration of the viral particles in the patient's abdomen by using a lower abdominal pressure during surgery, lesser usage of electrocautery, minimizing the duration of surgery, and by avoiding the contamination of sterile operation theater air by using ultra-low particulate air filter with smoke evacuation, so that the safety of the health care professionals can be ensured (class IIA, level C-EO).

Prioritizing the health care professional's safety, delaying elective surgery has been recommended (class IIa, level C-LD), where it can be balanced with the risk of impending harm to the patient by delaying treatment. ${ }^{74,75}$ The choice of route of surgery should be individualized to the patient depending on

Table 8 Gynecological endoscopic surgery during COVID-19 era

\begin{tabular}{|l|l|}
\hline $\begin{array}{l}\text { Scientific statements on gynecological } \\
\text { endoscopic surgery during } \\
\text { COVID-19 pandemic }\end{array}$ & References \\
\hline $\begin{array}{l}\text { Preoperative clinical screening for symptoms of } \\
\text { COVID-19 and nasopharyngeal swab for reverse } \\
\text { transcriptase polymerase chain reaction are rec- } \\
\text { ommended. However, computed tomography of } \\
\text { the chest along with the above investigations can } \\
\text { be performed to increase further the sensitivity of } \\
\text { diagnosing COVID-19 infection }\end{array}$ & \\
\hline $\begin{array}{l}\text { The theoretical risk of dispersion of COVID-19 by } \\
\text { the carbon dioxide used to create pneumoperito- } \\
\text { neum from the patient's abdomen to the outside } \\
\text { environmental air has to be considered. Effective } \\
\text { systems should be in place for proper smoke } \\
\text { evacuation and filtration }\end{array}$ & 72,73 \\
\hline $\begin{array}{l}\text { Gynecologic endoscopic surgery can be considered } \\
\text { to be safe when performed cautiously with the } \\
\text { usage of personal protective equipment. However, } \\
\text { alternative routes of surgery like laparotomy and } \\
\text { vaginal surgery can be considered in appropriate } \\
\text { situations, especially when resources are limited }\end{array}$ & \\
\hline
\end{tabular}

Abbreviation: COVID-19, novel coronavirus disease 2019. the indication for surgery, associated comorbidity, the likelihood of COVID-19 infection based on preoperative screening, the urgency of surgery, and most importantly, the availability of resources to the operating team.

\section{COVID-19 Infections in Pregnancy}

In this study, scientific statements are made on the vertical transmission of COVID-19 to fetus in utero, the need for universal testing for COVID-19 before entering the labor room, and the preferred mode of delivery in COVID-19-positive pregnant ladies (-Table 9).

Clinical manifestations of COVID-19 in pregnant females seem to be similar to females who are not pregnant. However, since pregnancy itself alters the body's immune system and response to viral infections in general, COVID-19 infection during pregnancy can be related to more severe symptoms. ${ }^{76,77}$

Not all pregnant women are more susceptible to complications due to COVID-19. Pregnant women over the age of 35 years, overweight or obese women, and those who have preexisting medical problems, such as high blood pressure, diabetes, respiratory problems, and heart disease, are at a higher risk of developing severe illness. ${ }^{78}$

All patients should be screened for signs and symptoms of COVID-19, as well as whether they have had close contact with a confirmed case, or persons under investigation, before entering the hospital for admission to the labor and delivery unit. Where testing capacity allows, universal testing of all pregnant women presenting for labor admissions should be performed due to the likely high rate of asymptomatic COVID-19-positive patients. . $^{790}$

Vertical transmission of the disease from the mother to the baby in utero or during childbirth is possible. However, the proportion of pregnancies affected and the significance to the neonate is yet to be determined. ${ }^{81,82}$

Mode of birth should not be influenced by the presence of COVID-19 unless the woman's respiratory condition demands urgent delivery. ${ }^{83}$

All patients should be screened for signs and symptoms of COVID-19 and whether they have had close contact with a

Table 9 COVID-19 infections in pregnancy

\begin{tabular}{|l|l|}
\hline $\begin{array}{l}\text { Scientific statements on } \\
\text { COVID-19 infections in pregnancy }\end{array}$ & References \\
\hline $\begin{array}{l}\text { COVID-19 infection during pregnancy may pro- } \\
\text { duce more severe symptoms }\end{array}$ & 76,77 \\
\hline $\begin{array}{l}\text { Pregnant women with high-risk category } \\
\text { (described in the text) require more attention as } \\
\text { these women are at a higher risk of developing } \\
\text { severe illness }\end{array}$ & 78 \\
\hline $\begin{array}{l}\text { All pregnant women should be screened for signs } \\
\text { and symptoms of COVID-19 }\end{array}$ & 79,80 \\
\hline $\begin{array}{l}\text { There is a possibility of vertical transmission from } \\
\text { mother to fetus in utero or during childbirth }\end{array}$ & 81,82 \\
\hline $\begin{array}{l}\text { Mode of birth should not be influenced by the } \\
\text { presence of COVID-19 unless the woman's res- } \\
\text { piratory condition demands urgent delivery }\end{array}$ & 83 \\
\hline $\begin{array}{l}\text { Universal testing of pregnant women for } \\
\text { COVID-19 at admission to labor suite is required }\end{array}$ & 79,80 \\
\hline
\end{tabular}

Abbreviation: COVID-19, novel coronavirus disease 2019. 
confirmed case or persons under investigation, before entering the hospital for admission to the labor and delivery unit.

Where testing capacity allows, universal testing of all pregnant women presenting for labor admissions should be performed due to the likely high rate of asymptomatic COVID-19-positive patients. ${ }^{79,80}$

\section{Infertility Treatment in COVID-19 Pandemic}

There is a controversy that infertility treatment is not an urgent modality of treatment, and whether it should be encouraged during this pandemic or not. A review on this topic was discussed in this special issue. Here are the scientific statements on this ( $\mathbf{- T a b l e ~ 1 0 ) . ~}$

Due to the current situation in the COVID-19 pandemic and the relaxation permitted by the government gradually permitting nonessential services, infertility services are being resumed according to the guidelines set by the Ministry of Health and Family Welfare. Patient selection and prioritization for fertility services should be based on the impact of delay on patient prognosis due to medical factors such as age, ovarian reserve, or endometriosis, and patients' mental and emotional wellbeing. Assisted reproductive treatment (ART) cycles for fertility preservation in cancer survivors to be started at the earliest (level IIB, evidence C). High-risk patients (those with hypertension, diabetes, on immunosuppressants, or transplant patients, with renal, liver, lung disease, or medical conditions) should be deferred for treatment during this period. ${ }^{84}$

Diagnostic evaluation for COVID-19 testing is done using RT-PCR, and the testing should be done at the commencement of treatment, that is, on day 2 of the in vitro fertilization (IVF)/intracytoplasmic sperm injection (ICSI) cycle (level IIB, evidence C), in the center where the COVID-19 test takes more than 24 hours, the test can be done 1 to 2 days prior. A repeat test is done before the human chorionic gonadotropin (hCG) trigger. If a patient comes out to be positive, the cycle should be canceled. ${ }^{85}$

Table 10 COVID-19 infections and infertility treatment

\begin{tabular}{|l|l|}
\hline $\begin{array}{l}\text { Scientific statements on } \\
\text { COVID-19 infections and infertility } \\
\text { treatment }\end{array}$ & References \\
\hline $\begin{array}{l}\text { Infertility IVF services should be reopened, espe- } \\
\text { cially for patients with a decreased ovarian reserve } \\
\text { and those requiring fertility preservation such } \\
\text { as cancer survivors, after proper counseling and } \\
\text { individualizing a case }\end{array}$ & 84 \\
\hline $\begin{array}{l}\text { The COVID-19 testing should be done on day } 2 \text { of } \\
\text { the cycle before ovarian stimulation and should be } \\
\text { repeated } 24 \text { hours prior to the ovarian trigger }\end{array}$ & 85 \\
\hline $\begin{array}{l}\text { The husband also needs testing at least once } \\
\text { during the cycle }\end{array}$ & 85 \\
\hline $\begin{array}{l}\text { COVID-19 testing should be done for all patients } \\
\text { undergoing infertility-related procedures such as } \\
\text { semen analysis, hysterosalpingography, hysteros- } \\
\text { copy, laparoscopy, ovulation-induction, intrauter- } \\
\text { ine insemination }\end{array}$ & 86 \\
\hline
\end{tabular}

Abbreviations: COVID-19, novel coronavirus disease 2019; IVF, in vitro fertilization.
The husband also needs testing at least once during the cycle (level IIB, evidence C), preferably at the start of the cycle. Before embryo transfer, COVID-19 testing is done approximately 1 to 2 days before the procedure. In case either partner turns positive on tests, they should help in contact tracing in keeping with the national policy. ${ }^{85}$

Currently, very little is known about the impact of COVID-19 on reproduction and pregnancy. There are reports of women who have tested positive for COVID-19, they have delivered babies free of disease. Ideally, pregnancy should not be allowed in COVID-19-positive patients, and infertility procedures in these patients are futile. ${ }^{86}$ So, COVID-19 testing should be done for all patients undergoing infertility-related procedures (level Ila, evidence B).

\section{Endocrinology}

Endocrine Diseases in Women and COVID-19 Infection

Here, we discuss the management modalities and follow-up of nonpregnant and pregnant women with diabetes, including gestational diabetes (- Table 11).

Diabetes has been associated with greater morbidity and mortality from COVID-19 infection with increased

Table 11 COVID-19 infections and endocrine diseases

\begin{tabular}{|c|c|}
\hline $\begin{array}{l}\text { Scientific statements on } \\
\text { COVID-19 infections and endocrine diseases }\end{array}$ & References \\
\hline $\begin{array}{l}\text { Insulin should be the mainstay for hyperglycemia } \\
\text { treatment in women who develop moderate to } \\
\text { severe COVID-19 infection. Persons infected with } \\
\text { COVID-19 infection are at increased risk of wors- } \\
\text { ening of hyperglycemia in pre-existing diabetes } \\
\text { or ocurrence of stress hyperglycemia as well as de } \\
\text { novo diabetes mellitus. Therefore, capillary blood } \\
\text { glucose monitoring should be intensified during } \\
\text { COVID-19 to guide and titrate insulin therapy. } \\
\text { Continued glucose monitoring is required after } \\
\text { recovery to determine long-term glycemic status } \\
\text { and guide treatment }\end{array}$ & $87-90$ \\
\hline $\begin{array}{l}\text { Pregnant women should continue to receive } \\
\text { optimal diabetes care during the pandemic with } \\
\text { advice on nutrition, self-monitoring of blood } \\
\text { glucose, and insulin therapy, where required. To } \\
\text { minimize the chances of inadvertent exposure to } \\
\text { infection during clinic visits, telemedicine services } \\
\text { should be considered for all pregnant women } \\
\text { with diabetes for remote monitoring of glycemic } \\
\text { control and insulin dose titration }\end{array}$ & $91-94$ \\
\hline $\begin{array}{l}\text { For routine screening of pregnant women } \\
\text { for gestational diabetes mellitus, alternative } \\
\text { screening strategies such as fasting plasma } \\
\text { glucose }(\geq 100 \mathrm{mg} / \mathrm{dL} \text { ) and glycosylated hemo- } \\
\text { globin }(\geq 5.7 \%) \text { should be considered in place of } \\
\text { oral glucose tolerance test (OGTT) to minimize } \\
\text { chances of exposure of pregnant women to } \\
\text { COVID-19 infection }\end{array}$ & $95-99$ \\
\hline $\begin{array}{l}\text { Women with adrenal insufficiency who develop } \\
\text { COVID- } 19 \text { infection need to increase the dose of } \\
\text { glucocorticoids (hydrocortisone } 20 \text { mg every } 6 \\
\text { hours) to reduce the adrenal crisis risk. In case of } \\
\text { severe infection or clinical deterioration, intrave- } \\
\text { nous glucocorticoid } 50 \text { mg every } 6 \text { hours or as } \\
\text { continuous infusion should be administered }\end{array}$ & $100-102$ \\
\hline
\end{tabular}

Abbreviation: COVID-19, novel coronavirus disease 2019. 
risk for hospitalization and intensive care unit admissions, respiratory distress and need for mechanical ventilation, cardiovascular involvement, acute kidney injury, and thrombotic events. ${ }^{87,88}$ COVID-19 infection may itself lead to worsening of hyperglycemia due to increased secretion of counter-regulatory hormones and cytokines and the use of medications, such as glucocorticoids, may impact glycemic control. ${ }^{87}$ Patients with mild infection who maintain adequate oral intake can continue previous antidiabetic medications with close self-monitoring of blood glucose (SMBG) and follow sick-day guidelines. ${ }^{88}$ However, insulin is the most effective and safe treatment for hyperglycemia management in persons with diabetes who develop moderate-to-severe COVID-19 infection..$^{87-90}$ For critically ill patients, insulin is administered as an intravenous insulin infusion with hourly blood glucose monitoring. However, in resource-limited settings where hourly blood glucose monitoring is not feasible, frequent bolus doses of rapid-acting insulin analogs given subcutaneously in every 4 to 6 hours can be considered. Insulin protocols can be tailored to the SMBG profile, dietary intake, and general well-being of the patient.

It is important to empower all pregnant women with diabetes regarding medical nutrition therapy, SMBG, insulin technique and administration, self-titration of insulin doses, and hypoglycemia recognition and management in the first clinical visit itself. Since physical visits to the clinic increase infection transmission risk, subsequent follow-up can be done via tele/video consultation. Physical visits to the diabetes care team can be timed along with visits to the obstetrician and ultrasounds. ${ }^{91-94}$

Oral glucose tolerance test (OGTT) at 24 to 28 weeks remains the gold standard for detecting gestational diabetes mellitus (GDM). However, as this would require repeated phlebotomy and more time spent at the specimen collection center, many experts have argued that this would increase the women's risk of acquiring COVID-19 infection. Therefore, many alternative screening strategies have been suggested by various countries. These include fasting plasma glucose and glycosylated hemoglobin (HbA1c) in place of OGTT as a temporary alternative measure to screen women for GDM. An HbA1c cut-off of 5.9\% and above, when measured by the National Glycohemoglobin Standardization Program (NGSP), certified method has been recommended to diagnose GDM during the pandemic. ${ }^{95-99}$

Any acute medical or surgical illness can precipitate an adrenal crisis episode in patients who have long-standing adrenal insufficiency. This is true for the COVID-19 infection as well. Therefore, patients who have primary or secondary adrenal insufficiency or those on long-term glucocorticoid therapy should be advised to use stress doses of glucocorticoids if they develop COVID-19 infection and contact their endocrine care provider. ${ }^{100-102}$ It is important for health care providers caring for COVID-19 infected patients to elicit any history or prior adrenal disease or glucocorticoid use and administer stress doses of steroids until the clinical condition improves. Glucocorticoids are also used in moderate to severe infection for their proposed benefits in improving outcomes by their immunomodulatory effects.

\section{Rheumatology}

Scientific Statements in Rheumatological Diseases with COVID-19

Here, scientific statements on the risk of COVID-19 in patients with rheumatic diseases, treatment of COVID-19 in patients with rheumatological diseases (RD) like drug dosage adjustments, and continuation of essential drugs are made

\section{(-Table 12).}

The risk of COVID-19 in RD similar or only slightly higher than that of the general population. There is a small increased risk in non-SLE systemic autoimmune disease. A higher steroid dose is a risk factor for severity. The risk with biologic disease modifying antirheumatic drugs (DMARDs) and targeted synthetic DMARDs are not clear. One study found patients on tumor necrosis factor (TNF) inhibitors to have lesser severity. The risk factors for COVID-19 are similar to the general population, including age, diabetes, cardiovascular comorbidity, and chronic lung disease. The effect of gender has not been specifically explored in rheumatic diseases compared with the general population. ${ }^{103-106}$

The clinical features of COVID-19 are similar in patients with RD. There is a higher risk of intensive care unit (ICU) admission and respiratory failure in patients with RD who develop COVID-19 compared with controls. Mortality is similar to non-RD patients. ${ }^{107,108}$

Testing for COVID-19 should be as per local guidelines. COVID-19 treatment should be the same in patients with RD as with non-RD. Biologic DMARDs and tsDMARDs except Tocilizumab may be interrupted. Steroids should not be stopped suddenly in patients on long term steroids. ${ }^{109,110}$

Treatment of stable RD should continue unchanged. It is unclear if there is an increased risk of COVID-19 in patients on biologics/tsDMARDs or any immunosuppression. Since

Table 12 COVID-19 infections and rheumatological diseases

\begin{tabular}{|l|l|}
\hline $\begin{array}{l}\text { Scientific statements on COVID-19 } \\
\text { infections and rheumatological } \\
\text { diseases (RD) }\end{array}$ & References \\
\hline $\begin{array}{l}\text { The risk of COVID-19 in RD is similar or slightly } \\
\text { higher than that of the general population, } \\
\text { especially in non-SLE systemic autoimmune } \\
\text { disease }\end{array}$ & $103-10^{6}$ \\
\hline $\begin{array}{l}\text { Even though there is a higher risk of ICU } \\
\text { admission and respiratory failure in patients with } \\
\text { RD who develop COVID-19 than controls, the } \\
\text { mortality is similar to non-RD patients }\end{array}$ & 107,108 \\
\hline $\begin{array}{l}\text { Steroids should not be interrupted in a patient } \\
\text { on long term steroids. Biologic DMARDs (disease } \\
\text { modifying antirheumatic drugs) and tsDMARDs } \\
\text { (targeted synthetic) except tocilizumab may be } \\
\text { interrupted if required }\end{array}$ & 108,109 \\
\hline $\begin{array}{l}\text { Higher doses of steroids are a risk factor for } \\
\text { COVID -19. There is no clear evidence that there } \\
\text { is an increased risk of COVID in patients on } \\
\text { biologics/ tsDMARDs or any immunosuppression }\end{array}$ & 108,109 \\
\hline
\end{tabular}

Abbreviations: COVID-19, novel coronavirus disease 2019; DMARDs, disease modifying antirheumatic drugs ICU, intensive care unit; 
higher doses of steroids are a risk factor for severity, the dose should be kept as low as necessary for disease control. Treatment of new/disease flare should be individualized. In stable patients with RD, teleconsultations may be done instead of in-person consultations. ${ }^{109,110}$

\section{Oncology \\ Care of Women with Gynecological Cancers during the COVID-19 Pandemic}

Here, scientific statements on cervical cancer, endometrial cancer, and epithelial ovarian cancer managements during COVID-19 are mentioned ( - Table 13 ).

Outcomes in gynecological cancers are heavily stage dependent, ranging from 5-year survival $95 \%$ in early stage to less than $15 \%$ in advanced stages. Early diagnosis and timely treatment are, therefore, of the utmost importance. Women in developing countries are an especially vulnerable group whose health care needs are often neglected. While it is prudent to suspend all screening services and evaluation of low grade lesions, all cases of invasive cervical cancers should preferably undergo diagnostic workup and treatment without delay. ${ }^{111,112}$ Depending on local pandemic factors and availability of expertise, radiotherapy and concomitant radiochemotherapy should replace surgery as first-line treatment whenever possible. Cervical cancer being a rapidly dividing tumor with a high potential for cure, there is no clinical situation where the treatment can be safely delayed. Hypofractionation schedules should be considered whenever feasible, and brachytherapy should not be delayed. ${ }^{113}$ All treatment should be preferably completed within 8 weeks, and delays should be avoided since they impact local control and survival.

All patients with abnormal uterine bleeding and suspected endometrial cancer should undergo endometrial biopsy without delay. Surgery should not be delayed in high risk patients with active bleeding. A short delay of less than 8 weeks can be considered in patients with clinically early disease without active bleeding. Patients with low risk grade- 1 disease may be offered hormonal therapy strategies like oral progestins or IUDs. Patients with higher risk disease (grade 2 or 3 or highrisk histology) should be considered for simple hysterectomy and bilateral salpingo-oophorectomy alone, with or without

Table 13 COVID-19 infections and gynecological cancers

\begin{tabular}{|l|l|}
\hline $\begin{array}{l}\text { Scientific statements on } \\
\text { COVID-19 infections and gynecological } \\
\text { cancers }\end{array}$ & References \\
\hline $\begin{array}{l}\text { Cervical cancer is an aggressive malignancy with } \\
\text { a good potential for cure in localized stages, and } \\
\text { should be treated without delay even during the } \\
\text { pandemic }\end{array}$ & $111-113$ \\
\hline $\begin{array}{l}\text { Management of women with endometrial cancer } \\
\text { during the COVID-19 pandemic should be based } \\
\text { on risk stratification }\end{array}$ & $111-113$ \\
\hline $\begin{array}{l}\text { Management of patients with epithelial ovarian } \\
\text { cancers should be individualized during the } \\
\text { COVID-19 pandemic based on risk versus benefit }\end{array}$ & $111,112,114$ \\
\hline
\end{tabular}

Abbreviation: COVID-19, novel coronavirus disease 2019. sentinel node sampling. The decision for adjuvant therapy should be based on risk factors. Patients with advanced disease should be considered for tissue biopsy to confirm diagnosis followed by systemic therapy. ${ }^{111,112}$ Hormonal therapy may be used in patients with endometrioid histology if adjuvant radiation needs to be delayed. ${ }^{113}$ Adjuvant radiation therapy may be delayed between 6 and 8 weeks following surgery in most cases. ${ }^{113}$ Adjuvant therapy might be deferred during the crisis in stage-I or -II disease with low-risk features, where as in cases with intermediate to high-risk features, Brachytherapy is preferred considering fewer hospital visits and lesser risk of complication. ${ }^{112}$ External beam radiotherapy with or without chemotherapy should be considered without any delay after surgery in high-risk patients and also for patients with symptomatic unresectable primary tumor not suitable for surgery. It may be prudent to increase the interval between chemotherapy cycles whenever deemed feasible.

Multiple factors, such as performance status, comorbidities, and family history, should be considered in patients with suspected ovarian cancer. Physical examination and a thorough diagnostic evaluation with pelvic ultrasound, CT/ magnetic resonance imaging (MRI), and/or serum markers, such as CA125 and HE4, to assess malignancy risk should be performed as early as feasible. ${ }^{112}$ In fit patients, surgery is considered mandatory if the disease is localized and limited to the pelvis and includes hysterectomy, bilateral salpingo-oophorectomy, and peritoneal staging. Lymphadenectomy may be avoided in low grade endometrial cancer due to its uncertain benefit. It can be considered in cases where the nodal status would help make decisions regarding adjuvant chemotherapy for ovarian cancers are best avoided during the COVID-19 pandemic. ${ }^{114}$

A tissue biopsy should be performed for confirmation in patients with clinically advanced-stage disease. In such cases, three to six cycles of neoadjuvant chemotherapy and delayed surgery are the recommended approaches since extensive surgical procedures can be risky for patients and health care workers during the pandemic. In patients receiving neoadjuvant chemotherapy, the treatment plan can be extended to six cycles, instead of three, before interval cytoreduction. This decision should be balanced against the additional risk of chemotherapy induced immunosuppression. ${ }^{111,112,114}$

Maintenance therapies following completion of adjuvant chemotherapy may be withheld, considering the additional risk of infection on the patient, families, and health care teams due to the need for repeated visits. ${ }^{112}$ In patients, active COVID-19 infection, surgery, and chemotherapy should be postponed till recovery. In general, extensive surgical procedures and highly immunosuppressive chemotherapy should be avoided during the outbreak whenever feasible. ${ }^{14}$

\section{Follow-up}

Surveillance can be deferred based on the level of risk of recurrence. In case of cervical cancer, patients treated with radical radiation therapy for early stage disease can be advised follow-up after 6 months. Follow-up visit after 
palliative treatment for advanced/recurrent disease can be postponed up to 2 months.

In case of endometrial cancer, follow-up can be converted to tele consultations, in intermediate-to-low risk patients. Follow-up visits (clinical and pelvic exam) in patients after palliative treatment for advanced/recurrent disease can be postponed up to 6 months in the absence of symptoms.

Follow-up visits can be converted to tele consultations, wherever feasible. Investigations like blood tests and imaging studies can be done in laboratories close to home and tele consultations provided.

\section{Care of Women with Breast Cancer during the COVID-19 Pandemic}

These are the scientific statements on diagnostic and staging procedures, surgical decisions, adjuvant postoperative radiation, and systemic therapies in breast cancer patients (-Table 14).

Current estimates suggest that the age-standardized incidence rate of breast cancer in India has increased significantly by $40 \cdot 7 \%$ from 1996 to $2016 .{ }^{115}$ It is currently the most common cancer in females, constituting about a fourth of cancers in them. ${ }^{116}$ Women in India often delay seeking medical care; therefore, a greater proportion present in advanced stages. Stigma, fear, denial, family responsibilities, embarrassment, and lack of affordability and access to care are significant reasons for the delay in diagnosis and treatment. ${ }^{117}$ Mandatory lockdowns can significantly limit access to care. ${ }^{118}$ Cancer treatment is time sensitive, and outcomes depend on the stage at presentation. Therefore, every effort should be made to ensure timely referral, workup, and treatment for patients suspected to have breast cancer while at the same time minimizing the risk of infection, reducing patient visits, and shifting to a quality system of telemedicine when appropriate. ${ }^{119}$ The Government of India has issued guidelines for telemedicine in March 2020. Economic obstacles can also prove a major deterrent in accessing care for India. ${ }^{117,118}$ Therefore, all stakeholders should work together to recognize women with cancer as a vulnerable population and put mechanisms in place to ensure affordability, accessibility, and continuity of care. ${ }^{118}$

Table 14 COVID-19 infections and breast cancers

\begin{tabular}{|l|l|}
\hline $\begin{array}{l}\text { Scientific statements on } \\
\text { COVID-19 infections and breast } \\
\text { cancers }\end{array}$ & References \\
\hline $\begin{array}{l}\text { Diagnostic and staging procedures for } \\
\text { suspected cases of breast cancer should be } \\
\text { prioritized, and any delay should be avoided }\end{array}$ & $115-119,160$ \\
\hline $\begin{array}{l}\text { Surgical decisions in patients with breast } \\
\text { cancer should be based on disease biology } \\
\text { and risk stratification }\end{array}$ & $119-121$ \\
\hline $\begin{array}{l}\text { Adjuvant post-operative radiation should } \\
\text { not be delayed for breast cancer patients } \\
\text { with high-risk features (described in the } \\
\text { text) }\end{array}$ & $122-126$ \\
\hline $\begin{array}{l}\text { Decisions regarding systemic therapies in } \\
\text { breast cancer during the COVID-19 pan- } \\
\text { demic should weigh the risk versus benefit }\end{array}$ & $119,120,127,161$ \\
\hline
\end{tabular}

Abbreviation: COVID-19, novel coronavirus disease 2019.
The surgery decision should be based on the status of the pandemic, availability of surgical expertise, and clinical condition of the patient. ${ }^{19,120}$ Many centers in India have canceled or postponed nonessential surgeries during the pandemic. Surgery during the pandemic carries a higher risk of postoperative morbidity. In many cases, neoadjuvant chemotherapy can be used to defer surgery while balancing the risks of immunosuppression due to chemotherapy. Neoadjuvant endocrine therapy can be used judiciously in hormone-receptor positive patients to delay surgery. ${ }^{121}$ Curative surgical procedures should be prioritized in patients who have completed neoadjuvant chemotherapy (NACT) and those who show the progression of NACT. All procedures for benign breast lesions or preinvasive low-grade cancers can be postponed. All prophylactic or reconstructive surgeries should be avoided during the pandemic. ${ }^{119,120}$

High-risk patients include those with T3/T4 tumors, high-grade tumors, node-positive disease, perinodal deposits, inflammatory breast cancer, triple-negative, or HER2-positive disease, residual disease at surgery postneoadjuvant therapy, and young age ( $<40$ years) at diagnosis. ${ }^{122}$ These patients should receive radiation therapy on schedule as delays can result in inferior survival outcomes. In patients with intermediate risk, radiation may be deferred for 3 to 6 months, depending on local circumstances. ${ }^{122,123}$ In such situations, the patients should receive oral endocrine therapy when eligible.

The use of hypofractionated regimens is strongly recommended, and the $40 \mathrm{~Gy}$ in 15 fractions schedule is suitable for most cases. In suitable patients, accelerated partial breast irradiation (APBI) ${ }^{124}$ or the five-fraction protocol of the FAST or FAST forward trials is strongly recommended. ${ }^{125,126}$ The omission of tumor bed boost is reasonable except in high-risk cases (young age, high-grade DCIS, etc.). Finally, radiation therapy can be omitted in low-risk disease patients who are elderly (age $>70$ years) or have significant comorbidities. ${ }^{123}$

During the pandemic, every effort must be made to limit infection risk for patients and health care personnel without compromising oncological outcomes. Several international oncological societies have issued recommendations for the prioritization of care of breast cancer patients. These guidelines need to be adapted to the local resources, health care delivery models, and local pandemic status. ${ }^{127}$ Chemotherapy decisions should consider the magnitude of benefit from the intervention versus the risk of immunosuppression and the disruption of life quality. In low-risk endocrine receptor positive patients, chemotherapy can be avoided because of uncertain benefits, and oral endocrine therapy must be started. Ongoing therapy should be continued in patients who are already on NACT or adjuvant chemotherapy. Two or three weekly schedules should be preferred over weekly schedules. Ongoing maintenance trastuzumab can be deferred for 6 to 8 weeks if necessary, and reducing the total duration of trastuzumab from 12 months to 6 months should be strongly considered. ${ }^{125}$ Strong consideration should be given to avoid highly immunosuppressive regimens when outcomes are not likely to be affected. Whenever possible oral agents should 
be preferred. Decisions should be made on a case-by-case basis keeping in mind the effects on quality of life and likely benefit versus harm. ${ }^{119,120,127}$ In general, administering mTOR inhibitors and immune checkpoint inhibitors should be avoided during the pandemic, given the higher risk of adverse outcomes with these agents. Bone-modifying agents like bisphosphonates or denosumab can be deferred in most cases. ${ }^{119,120}$

Finally, the decentralization of outpatient chemotherapy and remote monitoring services should be considered when travel to cancer centers is difficult, or the risk of infection is high. Stakeholders must work together to ensure an ongoing supply of essential oncology drugs during the pandemics as disruption of supply chains can lead to shortages/ nonavailability.

\section{Neurology}

\section{Scientific Statements on COVID-19 Infections and Neurological Disorders in Women}

In this, scientific statements on thrombolytic therapy in pregnant and nonpregnant women with stroke and the risk of developing cerebral venous sinus thrombosis in women with COVID-19 are mentioned (-Table 15).

It is well recognized that the quality of care for women with acute ischemic stroke is lower than that for their male counterparts. It is reasonable to treat otherwise eligible pregnant/ menstruating women with thrombolytic therapy as per the available guidelines for the early management of acute ischemic stroke ${ }^{128}$ (class IIa, level C-EO). Various international and Indian guidelines have advocated thrombolytic therapy in COVID-19 suspect/positive patients with acute ischemic stroke. ${ }^{129-131}$ There have been concerns surrounding disseminated intravascular coagulation in COVID-19 and the risks of excessive bleeding in these patients. However, COVID-19induced coagulopathy $(\mathrm{CIC})$ appears to be more prothrombotic than hemorrhagic. ${ }^{132}$ Though specific thrombolytic

Table 15 COVID-19 infections and neurological disorders in women

\begin{tabular}{|l|l|}
\hline $\begin{array}{l}\text { Scientific statements on } \\
\text { COVID-19 infections and neurological } \\
\text { disorders in women }\end{array}$ & References \\
\hline $\begin{array}{l}\text { Thrombolytic therapy is probably indicated in } \\
\text { otherwise eligible COVID-19 suspect/positive } \\
\text { women with acute ischemic stroke who are } \\
\text { menstruating and do not have a history of } \\
\text { menorrhagia after ruling out any additional } \\
\text { contraindications like coagulopathy }\end{array}$ & \\
\hline $\begin{array}{l}\text { Thrombolytic therapy for moderate and severe } \\
\text { stroke may be considered in pregnant COVID- }\end{array}$ & $128-130,162$ \\
$\begin{array}{l}19 \text { suspect/ positive women when the likely } \\
\text { benefits of stroke treatment outweigh the } \\
\text { anticipated bleeding risks (uterine bleeding) }\end{array}$ & \\
\hline $\begin{array}{l}\text { SARS-CoV-2 infection may further increase the } \\
\text { risk of developing cerebral venous sinus throm- } \\
\text { bosis in women consuming oral contraceptive } \\
\text { pills (OCP) }\end{array}$ & \\
\hline
\end{tabular}

Abbreviations: COVID-19, novel coronavirus disease 2019; SARS-CoV-2, severe acute respiratory syndrome-coronavirus- 2 . therapy data on COVID-19-positive pregnant stroke patients is not available, it seems reasonable that the eligible pregnant stroke patients should benefit from thrombolytic therapy. Risks of additional bleeding should be assessed in menstruating women with stroke before offering thrombolytic therapy (class IIb, level C-LD).

COVID-19 associated coagulopathy increases the risks of the development of thrombotic phenomena. Cerebral venous sinus thrombosis due to SARS-CoV-2 infection has been reported repeatedly during this pandemic. ${ }^{131-133}$ Oral contraceptive pills (OCP) consumption is a well-recognized risk factor for development of CVT. ${ }^{134}$ Increased thrombosis is expected if both the risk factors are combined (class IIa, level C).

\section{Preventive Medicine \\ Key Considerations for the Safety of Health Care Workers}

Nearly $70 \%$ of health care workers are females in this COVID-19 pandemic and special attention is to be paid to them. Here, scientific statements on menstrual health and hygiene (MHH) while using PPE kits and HCQ prophylaxes for female health care workers are mentioned (-Table 16).

Table 16 COVID-19 infections and the safety of health care workers

\begin{tabular}{|l|l|}
\hline $\begin{array}{l}\text { Scientific statements on } \\
\text { COVID-19 infections and the safety of health } \\
\text { care workers }\end{array}$ & References \\
\hline $\begin{array}{l}\text { The wearing of PPE kits for long durations ( } 8 \text { hours } \\
\text { or more) in female healthcare workers leads to } \\
\text { problems in menstrual health and hygiene (MHH). } \\
\text { Hence, duty hours should be reduced to } 4 \text { hours } \\
\text { while simultaneously ensuring MHH and wash } \\
\text { facilities }\end{array}$ & \\
\hline $\begin{array}{l}\text { HCQ prophylaxis should be recommended to all } \\
\text { healthcare workers working in COVID-19 and } \\
\text { non-COVID-19 healthcare settings for } 8 \text { weeks } \\
\text { and more }\end{array}$ & 138,139 \\
\hline $\begin{array}{l}\text { HCQ prophylaxis in female healthcare workers, } \\
\text { during pregnancy, should be continued }\end{array}$ & 140 \\
\hline $\begin{array}{l}\text { Relative infant dose (RID) must be the critical } \\
\text { parameter and should be calculated if HCQ proph- } \\
\text { ylaxis needs to be given in lactating health care } \\
\text { worker, for postexposure prophylaxis }\end{array}$ & 141,142 \\
\hline $\begin{array}{l}\text { Menstrual hygiene materials and painkillers should } \\
\text { be provided to female patients quarantined in } \\
\text { health care facilities or COVID-19 designated } \\
\text { centers and training of caretakers and support for } \\
\text { water sanitation and hygiene (wash) }\end{array}$ & \\
\hline $\begin{array}{l}\text { Materials for maintaining menstrual health and } \\
\text { hygiene should be available in sufficient quantities } \\
\text { for female healthcare workers during menstru- } \\
\text { ation. This should be provided by the health } \\
\text { department or facility to avoid women bleeding } \\
\text { into PPE suits during menstruation or to avoid } \\
\text { unwilling suppression of menstruation with oral } \\
\text { contraceptive pills }\end{array}$ & \\
\hline
\end{tabular}

Abbreviations: COVID-19, novel coronavirus disease 2019; HCQ, hydroxychloroquine; PPE, personal protective equipment. 
The wearing of PPE kits for long durations ( 8 hours or more) in female health care workers leads to problems in $\mathrm{MHH}$. Hence, duty hours for them should be reduced to 4 hours, while simultaneously also ensuring $\mathrm{MHH}$ and wash facilities. (class I, level EO). The COVID-19 response, depending on the intensity of the disease, and subsequent measures taken by each country, can result in mild to severe disruption of necessary facilities like water sanitization and hygiene (WASH), and can also lead to a reduction in the capacity of individuals to have free access to such services. ${ }^{135}$ This poses a special challenge to female health care workers, since globally, women make up $70 \%$ of the health workforce. ${ }^{136}$ In addition to those mentioned above, COVID-19 also imposes additional challenges to women, in terms of managing their menstrual hygiene, which, often compromises their health, dignity, and the ability of the health care system to function optimally. ${ }^{137}$ Therefore, it is strongly recommended that a stable supply of MHH and WASH facilities is ensured to female workers, and that their working hours are reduced.

The absence of a vaccine makes the medical and scientific community look carefully, closely, and intensely at a drug that can potentially be used for pre- and postexposure prophylaxis in the COVID-19 pandemic. The systemic review of 41 interventional studies registered in governmental clinical trials was undertaken to analyze the positioning of HCQ for COVID-19 prophylaxis in exposed health care workers. ${ }^{138}$ The National Task Force issued guidelines regarding the extended use of HCQ prophylaxis beyond 8 weeks, ${ }^{139}$ making it a well-recommended drug (class I, level A).

There appears no need to discontinue HCQ during pregnancy as the former has no adverse effects on fetal outcomes. It is recommended that HCQ should be given with caution in breastfeeding and lactating health care workers (class IIa, level A). In addition to that, it is recommended to calculate relative infant dose (RID) in postexposure prophylaxis in female healthcare workers, who are breastfeeding. (RID, dose offered to the infant via breast milk divided by the mother's weight; class I, level A). ${ }^{140}$

According to the policies of the Ministry of Health and Family Welfare regarding COVID-19, all suspects and contacts of COVID-19 cases are being quarantined in health care facilities or COVID-19 designated areas. This is especially challenging in the case of female patients who require access to WASH and MHH supplies. A joint report published in 2019 by WHO and UNICEF outlines that WASH services in many health care facilities across the world are missing or substandard. Menstrual hygiene materials and painkillers for symptomatic relief should be part of essential items provided at health care facilities and quarantine centers for female patients. Caretakers appointed in theses facilities should be provided with training to assist and educate girls and women with personal and menstrual hygiene. ${ }^{141,142}$

Women constitute the majority of the health workforce, and they are more likely to be at the front line in this COVID-19 pandemic. They have to face additional challenges compared with their male counterparts in the form of managing their menstruation. It compromises their ability to deliver effective health care services and their health and dignity. Menstrual hygiene materials should be considered as essential supplies for female health care providers. It should be procured in sufficient quantity and of good quality by the concerned health department or facility. Since donning and doffing PPE prevents frequent changing of menstrual hygiene materials, access to an adequate PPE quantity would allow them to take breaks at least every 4 hours to change tampons or high absorbency pads. Ensure health facilities are women employee friendly and they have access to water sanitation and hygiene in health care facilities ${ }^{141}$

\section{Research}

\section{COVID-19 Infections and Research}

Here, scientific statements on recent advances in understanding genome sequences of SARS-CoV-2, and causes for female gender protection and male gender predilection are mentioned (- Table 17).

Genome sequences of SARS-CoV-2 from across the world show that they originate from two ancestral lineages $A$ and $B$. Clade A2a, which arose from lineage $A$, is now the most prevalent clade of SARS-CoV-2 throughout the world. The disparity in COVID-19 manifestation in the severity of the disease or mortality does not seem to be because of the difference in the virus. ${ }^{143-147}$

SARS-CoV-2 enters host cells through binding ACE-2 receptors expressed on the cell surfaces. Men have shown to express higher levels of ACE2 on lung epithelial cells and in soluble form. ACE-2 has also been shown to be downregulated by estrogen. TMPRSS, a protease, facilitates SARS-CoV-2 binding with ACE2. TMPRSS gene has an androgen-regulated element. These are the most established reasons men get higher SARS-CoV-2 infections than women. ${ }^{148-155}$

Estrogen and testosterone have differential effects on immunity. The former strengthens immunity, and the latter diminishes it. Many other proteins involved in immune reactions are expressed on X-chromosome. With two allelic options for X-chromosome genes and X-chromosome inactivation in their cells, women are believed to be at an immune advantage. The role of these in protecting women from

Table 17 Research in COVID-19

\begin{tabular}{|l|l|}
\hline $\begin{array}{l}\text { Scientific statements on } \\
\text { COVID-19 infections and research }\end{array}$ & References \\
\hline $\begin{array}{l}\text { The disparity in COVID-19 manifestation in the } \\
\text { severity of the disease or mortality does not } \\
\text { seem to be because of differences in the virus } \\
\text { (different clades) }\end{array}$ & $140-147$ \\
\hline $\begin{array}{l}\text { Men get higher SARS-CoV-2 infections than } \\
\text { women due to higher levels of ACE-2 on lung } \\
\text { epithelial cells and TMPRSS gene (androgen-de- } \\
\text { pendent) which facilitates SARS-CoV-2 binding } \\
\text { with ACE-2 }\end{array}$ & $145-155$ \\
\hline $\begin{array}{l}\text { Women may be protected from SARS- } \\
\text { CoV-2 infections, which may be due to immune } \\
\text { advantage (details are given in the text) }\end{array}$ & $153-159$ \\
\hline
\end{tabular}

Abbreviations: ACE2, angiotensin converting enzyme 2; COVID-19, novel coronavirus disease 2019; SARS-CoV-2, severe acute respiratory syndrome-coronavirus- 2 . 
SARS-CoV-2 infection or severity of COVID-19 is yet to be studied and understood. ${ }^{156-159}$

\section{Concordance with the Expert's Opinion}

The formulation of scientific statements by the panel was followed by the circulation of the given statements to an expert group in respective branches in the form of a questionnaire. The questionnaire was given in yes or no format. The concordance rate was then calculated for every scientific statement and tabulated. The concordance rate was defined as the percent of cases in which both member pairs share a particular attribute. All questions asked, and the average responses are mentioned in concordance tables, in -Appendix $\mathbf{3}$ (available online only). The average concordance rate for each subject was calculated by averaging all concordant responses to questions.

The number of experts contacted was 22 in cardiology, 22 in preventive medicine, 45 in endocrinology, 13 in rheumatology, 20 in gynobs (gynecology and obstetrics), 32 in internal medicine, and 17 in neurology. The average accordance was maximum with rheumatology scientific statements (95.20\%), followed by endocrinology (92.29\%), preventive medicine (92\%), internal medicine (81.90\%), cardiology (64.95\%), neurology (68\%), and gynobs (57\%), respectively.

This methodology of data collection via questionnaire from experts is fraught with certain limitations. First, the experts were not informed beforehand about the details of this study. All of them were requested to respond within 5 days. So, this may be the doctors; opinion with their existing knowledge that is based on complete review of the literature. Moreover, a short duration of 5 days was permitted for responding to the questionnaire, which would herby be a mere opinion of physicians and not reflect a complete review of the literature. Second, few questions were left unanswered and blank by the experts. This could reflect a physician's unawareness of that particular topic or a drawback of the binominal yes or no format of the questionnaire, not allowing them to submit their opinion. Third, in - Appendix 4 (available online only), explanations for discordance are given. Despite of these gross limitations, the opinion poll was utilized to the direct for the strength of each scientific statement. In -Appendix 5 (available online only), definition of class of recommendation and level of evidence is mentioned.

\section{Conclusion}

Variant gender-specific and gender-frequent manifestations of diseases in the female population, especially in the COVID19 pandemic era make it imperative to lay down a management strategy and approach for targeting this population. Besides describing, managing and prognosticating these diseases in women in COVID-19 pandemic, these scientific statements also draw attention to the female health workers requirement which has usually been an area of neglect. This paper attempts to tide over the existing knowledge gap in the arena of women health in COVID-19 era which has so far been untouched and not discussed.

\section{Conflict of Interest}

None declared.

\section{Acknowledgment}

We want to acknowledge all the following doctors for valuable advises in preparation of the scientific statements, reviewing the article and excellent guidance at each step.

Prof. Krishnam Raju (Chief Cardiologist-Previous President of IAE), Prof. M.K. Das (Chief Cardiologist-CSI President), Prof. Gurpreet Singh Wander (Chief CardiologistBCRoy National Awardee, CSI Executive Committee Member), Prof. Alpesh Gandhi (Chief Gynecologist-FOGSI President Elect), Prof. Padmaja (Chief Gynecologist), Prof. Manjeesh Tiwasker (Chief Internist-API General Secretary), Prof. Satyanarayana Raju (Chief Internist-API Vice President), Prof. Vitul K. Gupta (Senior Internist-CSI Executive Committee Member), Prof. Sanjay Kalara (Chief Endocrinologist-ESI President), Prof. Rakesh Sahay (Chief Endocrinologist-ESI Vice President), Prof. PV Rao (Chief Endocrinologist-ESI Previous President), Prof. Pramod Pal (Chief Neurologist-IAN President), Prof. J.M.K. Murthy (Chief Neurologist-IAN President Elect), Prof. Sapan Pandya (Chief Rheumatologist-IRA Secretary), Prof. Alakendughosh (Chief Rheumatologist-IRA President), Prof. Urk Rao (Chief Rheumatologist-IRA Former President), Prof. Kaushik Bhattacharya (Chief Oncologist-General Secretary AROITS) And Prof. Sanjeeva Kumari (Chief Radiation Oncologist).

\section{References,}

1 Bikdeli B, Madhavan MV, Jimenez D, et al; Global COVID-19 Thrombosis Collaborative Group, Endorsed by the ISTH, NATF, ESVM, and the IUA, Supported by the ESC Working Group on Pulmonary Circulation and Right Ventricular Function. COVID-19 and Thrombotic or Thromboembolic Disease: Implications for Prevention, Antithrombotic Therapy, and Follow-Up: JACC State-of-the-Art Review. J Am Coll Cardiol 2020;75(23):2950-2973

2 Thangaratinam S, WE Redman C. The Delphi technique. Obstet Gynaecol 2005; 7:120-125

$3 \mathrm{Wu}$ M, Huang S, Liu J, et al. Association between comorbidities and the risk of death in patients with COVID-19: sex-specific differences. 2020;; doi: 10.1101/2020.05.22.20109579

4 Zhou F, Yu T, Du R, et al. Clinical course and risk factors for mortality of adult inpatients with COVID-19 in Wuhan, China: a retrospective cohort study. Lancet 2020;395(10229): 1054-1062

5 Shi S, Qin M, Shen B, et al. Association of cardiac injury with mortality in hospitalized patients with COVID-19 in Wuhan, China. JAMA Cardiol 2020;5(7):802-810

6 Shi S, Qin M, Cai Y, et al. Characteristics and clinical significance of myocardial injury in patients with severe coronavirus disease 2019. Eur Heart J 2020;41(22):2070-2079

7 Lala A, Johnson KW, Januzzi JL, et al; Mount Sinai COVID Informatics Center. Prevalence and impact of myocardial injury in patients hospitalized with COVID-19 infection. J Am Coll Cardiol 2020;76(5):533-546

8 Bangalore S, Sharma A, Slotwiner A, et al. ST-segment elevation in patients with COVID-19 - a case series. N Engl J Med 2020; 382(25):2478-2480

9 Stefanini GG, Montorfano M, Trabattoni D, et al. ST-elevation myocardial infarction in patients with COVID-19: clinical and angiographic outcomes. Circulation 2020;141(25): 2113-2116 
10 Hamadeh A, Aldujeli A, Briedis K, et al. Characteristics and outcomes in patients presenting with COVID-19 and ST-segment elevation myocardial infarction. Am J Cardiol 2020;131:1-6

11 Loghin C, Chauhan S, Lawless SM. Pseudo-acute myocardial infarction in a young COVID-19 patient. JACC Case Rep 2020; 2(9):1284-1288

12 Zendjebil S, Zeitouni M, Batonga M, et al. Acute multi-vessel coronary occlusion revealing COVID-19 in a young adult. JACC Case Rep 2020;2(9):1297-1301

13 Guagliumi G, Sonzogni A, Pescetelli I, Pellegrini D, Finn AV. Microthrombi and ST-segment elevation myocardial infarction in COVID-19. Circulation 2020;142(8):804-809

14 Kerkar PG, Naik N, Alexander T, et al. Cardiological Society of India: document on acute MI care during COVID-19. Indian Heart J 2020;72(2):70-74

15 Mohanan PP, Mathew R, Harikrishnan S, et al; Kerala ACS Registry Investigators. Presentation, management, and outcomes of 25748 acute coronary syndrome admissions in Kerala, India: results from the Kerala ACS Registry. Eur Heart J 2013;34(2):121-129

16 ESC Guidance for the Diagnosis and Management of CV Disease during the COVID-19 pandemic. Available at: https:// www.escardio.org/Education/COVID-19-and-Cardiology/ESCCOVID-19-Guidance.Accessed September 17, 2020

17 Hunt B, Retter A, McClintock C. Practical guidance for the prevention of thrombosis and management of coagulopathy and disseminated intravascular coagulation of patients infected with COVID-19. Available at: https://b-s-h.org. uk/media/18171/th-and-covid-25-march-2020-final.pdf. Accessed 2020 April 29

18 Cui S, Chen S, Li X, Liu S, Wang F. Prevalence of venous thromboembolism in patients with severe novel coronavirus pneumonia. J Thromb Haemost 2020;18(6):1421-1424

19 Spiezia L, Boscolo A, Poletto F, et al. COVID-19-related severe hypercoagulability in patients admitted to intensive care unit for acute respiratory failure. Thromb Haemost 2020;120(6):998-1000

20 Ranucci M, Ballotta A, Di Dedda U, et al. The procoagulant pattern of patients with COVID-19 acute respiratory distress syndrome. J Thromb Haemost 2020;18(7):1747-1751

21 Fontana P, Casini A, Robert-Ebadi H, Glauser F, Righini M, Blondon M. Venous thromboembolism in COVID-19: systematic review of reported risks and current guidelines. Swiss Med Wkly 2020;150:w20301

22 Marone EM, Bonalumi G, Curci R, et al. Characteristics of venous thromboembolism in COVID-19 patients: a ynaecologi experience from Northern Italy. Ann Vasc Surg 2020;:S0890-5096(20)30598-7

23 Stegeman BH, de Bastos M, Rosendaal FR, et al. Different combined oral contraceptives and the risk of venous thrombosis: systematic review and network meta-analysis. BMJ 2013;347:f5298

24 Rossouw JE, Prentice RL, Manson JE, et al. Postmenopausal hormone therapy and risk of cardiovascular disease by age and years since menopause. JAMA 2007;297(13):1465-1477

25 Struble E, Harrouk W, DeFelice A, Tesfamariam B. Nonclinical aspects of venous thrombosis in pregnancy. Birth Defects Res C Embryo Today 2015;105(3):190-200

26 Spratt DI, Buchsbaum RJ. COVID-19 and hypercoagulability: potential impact on management with oral contraceptives, estrogen therapy and pregnancy. Endocrinology 2020 (e-pub ahead of print). doi: https://doi.org/10.1210/endocr/ bqaa121

27 Chinese Medical Doctor Association. Prevention and treatment of new coronavirus pneumonia associated venous thromboembolism, a Consensus statement (Preliminary Protocol) Chinese Medical Journals Network 2020;:E007-E
28 Thachil J, Tang N, Gando S, et al. ISTH interim guidance on recognition and management of coagulopathy in COVID-19. J Thromb Haemost 2020;18(5):1023-1026

29 ZhaiZ, Li C, Chen Y, et al; Prevention Treatment of VTE Associated with COVID-19 Infection Consensus Statement Group. Prevention and treatment of venous thromboembolism associated with coronavirus disease 2019 infection: a consensus statement before guidelines. Thromb Haemost 2020;120(6): 937-948

30 GFHT/GIHP Propositions pour le treatment anticoagulant pour la ynaecolog du ynaec thrombotique chez un patient hospitalise avec COVID-19. Available at: https://site.geht.org/docutheque/. Accessed 2020 April 29

31 Vivas D, Roldán V, Esteve-Pastor MA, et al; Revisores expertos. [Recommendations on antithrombotic treatment during the COVID-19 pandemic. Position statement of the Working Group on Cardiovascular Thrombosis of the Spanish Society of Cardiology] (in Spanish) Rev Esp Cardiol 2020;73(9):749-757

32 Helms J, Tacquard C, Severac F, et al. CRICS TRIGGERSEP Group (Clinical Research in Intensive Care and Sepsis Trial Group for Global Evaluation and Re- search in Sepsis). High risk of thrombosis in patients with severe SARS- CoV-2 infection: a ynaecologi prospective cohort study. Intensive Care Med 2020;46(6):1089-1098

33 Oudkerk M, Büller HR, Kuijpers D, et al. Diagnosis, prevention, and treatment of thromboembolic complications in COVID-19: report of the national institute for public health of the Netherlands. Radiology 2020;0:201629

34 Casini A, Alberio L, Angelillo-Scherrer A, et al. Thromboprophylaxis and laboratory monitoring for in-hospital patients with COVID-19 - a Swiss consensus statement by the Working Party Hemostasis. Swiss Med Wkly 2020; 150:w20247

35 Ain DL, Albaghdadi M, Giri J, et al. Extra-corporeal membrane oxygenation and outcomes in massive pulmonary embolism: Two eras at an urban tertiary care hospital. Vasc Med 2018;23(1):60-64

36 COVID-19and VTE/Anticoagulation: Frequently Asked Questions. Available at: https://www.hematology.org/covid19/covid-19-and-vte-anticoagulation. Accessed September 17, 2020

37 Recommendations for thrombosis prophylaxis in SARS-CoV-2 (COVID-19) http://gth-online.org/wp-content/uploads/2020/04/GTH-EmpfehlungenCOVID-19.pdf 2020 April 1. Accessed 2020 April 29

38 Marietta M, Ageno W, Artoni A, et al. COVID-19 and haemostasis: a position paper from Italian Society on Thrombosis and Haemostasis (SISET) Blood Transfus 2020;18(3):167-169

39 Lippi G, Favaloro EJ. D-dimer is associated with severity of coronavirus disease 2019 (COVID- 19): a pooled analysis. Thromb Haemost 2020;120(5):876-878

40 Spyropoulos AC, Lipardi C, Xu J, et al. Improved benefit risk profile of rivaroxaban in a subpopulation of the MAGELLAN study. Clin Appl Thromb Hemost 2019;25:1076029619886022

41 Skeik N, Mirza A, Manunga J. Management of venous thromboembolism during the COVID-19 pandemic. J Vasc Surg Venous Lymphat Disord 2020;8(5):897-898

42 Updated: WHO Now Doesn't Recommend Avoiding Ibuprofen For COVID-19 Symptoms. Available at: https://www.sciencealert.com/who-recommends-to-avoid-taking-ibuprofenfor-covid-19-symptoms. Accessed August 2, 2020

43 Knight M, Bunch K, Vousden N, et al; UK Obstetric Surveillance System SARS-CoV-2 Infection in Pregnancy Collaborative Group. Characteristics and outcomes of pregnant women admitted to hospital with confirmed SARS-CoV-2 infection in UK: national population based cohort study. BMJ 2020;369:m2107 
44 Guo T, Fan Y, Chen M, et al. Cardiovascular implications of fatal outcomes of patients with coronavirus disease 2019 (COVID-19) JAMA Cardiol 2020;5(7):811-818

45 Jabri A, Kalra A, Kumar A, et al. Incidence of stress cardiomyopathy during the coronavirus disease 2019 pandemic. JAMA Netw Open 2020;3(7):e2014780

46 Mendoza M, Garcia-Ruiz I, Maiz N, et al. Pre-eclampsia-like syndrome induced by severe COVID-19: a prospective observational study. BJOG 2020 (e-pub ahead of print). doi: 10.1111/1471-0528.16339

47 American College of Obstetricians and Gynecologists. COVID-19 FAQs for obstetricians-gynecologists, obstetrics. Available at: https://www.acog.org/clinical-information/physician-faqs/covid-19-faqs-for-ob-gyns-obstetrics. Accessed on June 25, 2020

48 Royal College of Obstetricians and Gynaecologists (RCOG). Coronavirus (COVID-19) Infection in Pregnancy. Available at: https://www.rcog.org.uk/coronavirus-pregnancy. Accessed on June 25, 2020

49 EhNews Bureau.ICMR revises treatment protocol for COVID-190 patients. Available at: https://www.expresshealthcare. in/covid19-updates/icmr-revises-treatment-protocol-forcovid-19-patients/421792/. Accessed Jun 14, 2020

50 American College of Obstetricians and Gynecologists (ACOG). COVID-19. Available at: https://www.acog.org/topics/covid19. Accessed June 16, 2020

51 Li X, Wang Y, Agostinis P, et al. Is hydroxychloroquine beneficial for COVID-19 patients? Cell Death Dis 2020;11(7):512

52 Appropriate and Safe Conversion from Warfarin to a DOAC during the COVID-19 Pandemic. Available at: https://handbook.ggcmedicines.org.uk/guidelines/covid-19-coronavirus/conversion-from-warfarin-to-doac-covid-19/. Accessed September 17, 2020

53 Management of patients currently on warfarin during Covid19. Availableat: https://www.sps.nhs.uk/articles/management-of-patients-currently-on-warfarin-during-covid-19/. Accessed September 17, 2020

54 Hoeltzenbein M, Beck E, Rajwanshi R, et al. Tocilizumab use in pregnancy: Analysis of a global safety database including data from clinical trials and post-marketing data. Semin Arthritis Rheum 2016;46(2):238-245

55 Saito J, Yakuwa N, Kaneko K, et al. Tocilizumab during pregnancy and lactation: drug levels in maternal serum, cord blood, breast milk and infant serum. Rheumatology (Oxford) 2019;58(8):1505-1507

56 United States National Library of Medicine. “Toxnet. Toxicology Data Network. Available from: URL: http://toxnet.nlm.nih. gov/cgi-bin/sis/htmlgen?LACT." Accessed September 17, 2020

57 Wen J, Luo J, Huang W, Tang J, Zhou H, Zhang W. The pharmacological and physiological role of multidrug-resistant protein 4. J Pharmacol Exp Ther 2015;354(3):358-375

58 ICMR revises treatment protocol for Covid-19 patients, Jun 14, 2020. Available at: https://www.expresshealthcare.in/ covid19-updates/icmr-revises-treatment-protocol-for-covid19-patients/421792/. Accessed September 17, 2020

59 Madelain V, Nguyen TH, Olivo A, et al. Ebola virus infection: review of the pharmacokinetic and pharmacodynamic properties of drugs considered for testing in human efficacy trials. Clin Pharmacokinet 2016;55(8):907-923

60 Obach RS, Huynh P, Allen MC, Beedham C. Human liver aldehyde oxidase: inhibition by 239 drugs. J Clin Pharmacol 2004;44(1):7-19

61 George PM, Wells AU, Jenkins RG. Pulmonary fibrosis and COVID-19: the potential role for antifibrotic therapy. Lancet Respir Med 2020;8(8):807-815

62 Xi Z, Zhigang Z, Ting L. Post-inflammatory pulmonary fibrosis in a discharged COVID-19 patient: Effectively treated with
Pirfenidone. Archives of Pulmonology and Respiratory Care 2020;6(1):051-053

$63 \mathrm{Su} \mathrm{S}$, Shen J, Zhu L, et al. Involvement of digestive system in COVID-19: manifestations, pathology, management and challenges. Therap Adv Gastroenterol 2020;13:1756284820934626

64 Mao R, Qiu Y, He JS, et al. Manifestations and prognosis of gastrointestinal and liver involvement in patients with COVID-19: a systematic review and meta-analysis. Lancet Gastroenterol Hepatol 2020;5(7):667-678

65 Lamy P-J, Rébillard X, Vacherot F, de la Taille A. Androgenic hormones and the excess male mortality observed in COVID-19 patients: new convergent data. World J Urol 2020 (e-pub ahead of print). doi:10.1007/s00345-020-03284-y

66 Siddiqui HK, Mehra M. COVID-19 illness in native and immunosupressed states: a clinical-therapeutic staging proposal. J Heart Lung Transplant 2020;39(5):405-407

67 Government of India, Ministry of Health and Family Welfare, Directorate General of Health Services (EMR Division); Version 5; dated 03.07.20. Available at: https://www. mohfw.gov.in/pdf/UpdatedClinicalManagementProtocolfor COVID19dated03072020.pdf. Accessed August 27, 2020

68 Infectious Disease Society of America Guidelines on the treatment and Management of Patients with COVID-19 (updated18/6/2020) . Available at: https://www.moh. gov.sg/docs/librariesprovider5/clinical-evidence-summaries/baricitinib-for-covid-19-(updated-18-june-2020) 98b032d0121745a4a19f67e41c4ecbb2.pdf. Accessed August 27, 2020

69 Joint RCOG, BSGE and BGCS Guidance for the management of abnormal uterine bleeding in the evolving coronavirus (COVID-19) pandemic. Available at: https://www.rcog.org.uk/ globalassets/documents/guidelines/2020-05-21-joint-rcogbsge-bgcs-guidance-for-management-of-abnormal-uterinebleeding-aub-in-the-evolving-coronavirus-covid-19-pandemic-updated-final-180520.pdf. Accessed September 17, 2020

70 Gynecologic Oncology considerations during the COVID-19 pandemic. Available at: https://www.sgo.org/resources/gynonc-considerations-during-covid-19/. Accessed September 17, 2020

71 Liu R, Han H, Liu F, et al. Positive rate of RT-PCR detection of SARS-CoV-2 infection in 4880 cases from one hospital in Wuhan, China, from Jan to Feb 2020. Clin Chim Acta 2020;505:172-175

72 Liu Y, Song Y, Hu X, Yan L, Zhu X. Awareness of surgical smoke hazards and enhancement of surgical smoke prevention among the gynecologists. J Cancer 2019;10(12):2788-2799

73 Weld KJ, Dryer S, Ames CD, et al. Analysis of surgical smoke produced by various energy-based instruments and effect on laparoscopic visibility. J Endourol 2007;21(3):347-351

74 IAGE Good Clinical Practice Recommendations. (Version 1:16th April 2020) https://iageguidelines.blogspot.com/

75 AAGL - Elevating Gynecologic Surgery. Joint Society Statement on Elective Surgery during COVID-19 Pandemic. Available at: https://www.aagl.org/news/covid-19-joint-statement-onelective-surgeries/. Accessed March 25, 2020

76 Government of India, Ministry of Health \& Family Welfare, Directorate General of Health Services (EMR Division). Revised Guidelines on Clinical Management of COVID-19. Available at: https://www.mohfw.gov.in/pdf/RevisedNational ClinicalManagementGuidelineforCOVID1931032020.pdf. Accessed April 5, 2020.

77 Data on COVID-19 during Pregnancy: Tracking data on COVID-19 during pregnancy can protect pregnant women and their babies. Available at: https://www.cdc.gov/coronavirus/2019-ncov/cases-updates/special-populations/pregnancy-data-on-covid-19.html. Accessed August 19, 2020 
78 The Federation of Obstetric and Gynaecological Societies of India. Good Clinical Practice recommendation on Pregnancy with COVID-19 Infection. Version 1. Available at: https:// www.fogsi.org/wp-content/uploads/covid19/fogsi_gcpr_on_ pregnancy_with_COVID_19_version_1.pdf. Accessed on April 5,2020

79 Centers for Disease Control and Prevention. Interim infection prevention and control recommendations for healthcare personnel during the coronavirus disease 2019 (COVID-19) Pandemic. Available at: https://www.cdc.gov/coronavirus/2019-ncov/hcp/infection-control-recommendations.html. Accessed July 14, 2020

80 Breslin N, Baptiste C, Gyamfi-Bannerman C, et al. Coronavirus disease 2019 infection among asymptomatic and symptomatic pregnant women: two weeks of confirmed presentations to an affiliated pair of New York City hospitals. Am J Obstet Gynecol MFM 2020;2(2):100118

81 Vivanti AJ, Vauloup-Fellous C, Prevot S, et al. Transplacental transmission of SARS-CoV-2 infection. Nat Commun 2020;11(1):3572

82 Fornari F. Vertical transmission of COVID-19-a systematic review. Journal of Pediatrics, Perinatology and Child Health 2020;4:7-13

83 Medline Abstract' Coronavirus disease 2019 (COVID-19): Pregnancy issues'. Available at: https://www.uptodate.com/ contents/coronavirus-disease-2019-covid-19-pregnancy-issues/abstract/19. .Accessed July 02, 2020

84 Prasad S, Trivedi P, Malhotra N, et al. Joint IFS-ISAR-ACE recommendations on resuming/opening up assisted reproductive technology services. J Hum Reprod Sci 2020;13(2):82-88

85 The Association of Reproductive and Clinical Scientists (ARCS) and British Fertility Society (BFS) U.K. Best Practice Guidelines for Reintroduction of Routine Fertility Treatments during the COVID-19 Pandemic. Available at: https://www.rcpath.org/ uploads/assets/d512a1f4-18e0-46b9-be905ca885234631/ UK-best-practice-guidelines-for-reintroduction-of-routinefertility-treatments-during-the-COVID-19-pandemic.pdf. Accessed September 17, 2020

86 Schwartz DA, Graham AL. Potential maternal and infant outcomes from (Wuhan) coronavirus 2019-nCoV infecting pregnant women: lessons from SARS, MERS, and other human coronavirus infections. Viruses 2020;12(2):1-16

87 Korytkowski M, Antinori-Lent K, Drincic A, et al. A pragmatic approach to inpatient diabetes management during the COVID-19 pandemic. J Clin Endocrinol Metab 2020;105(9): dgaa342

88 Umpierrez GE, Hellman R, Korytkowski MT, et al; Endocrine Society. Management of hyperglycemia in hospitalized patients in non-critical care setting: an endocrine society clinical practice guideline. J Clin Endocrinol Metab 2012;97(1): 16-38

89 Bornstein SR, Rubino F, Khunti K, et al. Practical recommendations for the management of diabetes in patients with COVID19. Lancet Diabetes Endocrinol 2020;8(6):546-550

90 RSSDI Guidance for healthcare professionals on COVID-19. Available at: https://rssdi.in/newwebsite/pdfdata/Covid-19Guidance-Healthcare-Professionals.pdf. Accessed April 25, 2020

91 Murphy HR. Managing diabetes in pregnancy before, during, and after COVID-19. Diabetes Technol Ther 2020;22(6):454-461

92 Poon LC, Yang H, Kapur A, et al. Global interim guidance on coronavirus disease 2019 (COVID-19) during pregnancy and puerperium from FIGO and allied partners: Information for healthcare professionals. Int J Gynaecol Obstet 2020;149(3):273-286

93 Aziz A, Zork N, Aubey JJ, et al. Telehealth for high-risk pregnancies in the setting of the COVID-19 pandemic. Am J Perinatol 2020;37(8):800-80810.1055/s-0040-1712121
94 Torlone E, Sculli MA, Bonomo M, et al. Recommendations and management of hyperglycaemia in pregnancy during COVID19 pandemic in Italy. Diabetes Res Clin Pract 2020;166:108345

95 Yamamoto JM, Donovan LE, Feig DS, Berger H. Urgent Update Temporary Alternative Screening Strategy for Gestational Diabetes Screening during the COVID-19 Pandemic A Joint Consensus Statement from the Diabetes Canada Clinical Practice Guidelines Steering Committee and the Society of Obstetricians and Gynecologists of Canada. Available at: https:// sogc.org/common/Uploaded\%20files/GDM-COVID-19\% 20temporary\%20screening\%20guidelines\%20-\%2020200402\% 20Agreed\%20Final.pdf. Accessed April 252020

96 Ikomi A, Mannan S, Simon G, et al. Diagnosis of gestational diabetes during the pandemic: what is the risk of falling through the net? Diabet Med 2020;(e-pub ahead of print). doi: $10.1111 /$ dme.14346

97 Thangaratinam S, Cooray SD, Sukumar N, et al. ENDOCRINOLOGY IN THE TIME OF COVID-19: Diagnosis and management of gestational diabetes mellitus. Eur J Endocrinol 2020;183(2):G49-G56

98 McIntyre HD, Moses RG. The Diagnosis and Management of Gestational Diabetes Mellitus in the Context of the COVID-19 Pandemic. Diabetes Care 2020;43(7):1433-1434

99 McIntyre HD, Gibbons KS, Ma RCW, et al. Testing for gestational diabetes during the COVID-19 pandemic. An evaluation of proposed protocols for the United Kingdom, Canada and Australia. Diabetes Res Clin Pract 2020;167:108353

100 Puig-Domingo M, Marazuela M, Giustina A. COVID-19 and endocrine diseases. A statement from the European Society of Endocrinology. Endocrine 2020;68(1):2-5

101 Almeida MQ, Mendonca BB. Adrenal insufficiency and glucocorticoid use during the COVID-19 pandemic. Clinics (São Paulo) 2020;75:e2022

102 Arlt W, Baldeweg SE, Pearce SH, Simpson HL. Endocrinology in the time of COVID-19: Management of adrenal insufficiency. Eur J Endocrinol 2020;183(1):G25-G32

103 Favalli EG, Monti S, Ingegnoli F, Balduzzi S, Caporali R, Montecucco C. Incidence of COVID-19 in patients with rheumatic diseases treated with targeted immunosuppressive drugs: what can we learn from observational data? Arthritis Rheumatol 2020;(e-pub ahead of print). doi:10.1002/ art. 41388

104 Emmi G, Bettiol A, Mattioli I, et al. SARS-CoV-2 infection among patients with systemic autoimmune diseases. Autoimmun Rev 2020;19(7):102575

105 Gianfrancesco M, Hyrich KL, Al-Adely S, et al; COVID-19 Global Rheumatology Alliance. Characteristics associated with hospitalisation for COVID-19 in people with rheumatic disease: data from the COVID-19 Global Rheumatology Alliance physician-reported registry. Ann Rheum Dis 2020;79(7):859-866

106 Pablos JL, Abasolo L, Alvaro-Gracia JM, et al; RIER investigators group. Prevalence of hospital PCR-confirmed COVID-19 cases in patients with chronic inflammatory and autoimmune rheumatic diseases. Ann Rheum Dis 2020;79(9):1170-1173

107 Ye C, Cai S, Shen G, et al. Clinical features of rheumatic patients infected with COVID-19 in Wuhan, China. Ann Rheum Dis 2020;79(8):1007-1013

108 D’Silva KM, Serling-Boyd N, Wallwork R, et al. Clinical characteristics and outcomes of patients with coronavirus disease 2019 (COVID-19) and rheumatic disease: a comparative cohort study from a US 'hot spot'. Ann Rheum Dis 2020;79(9):1156-1162

109 NICE.COVID-19 rapid guideline: rheumatological autoimmune, inflammatory and metabolic bone disorders. Available at: https://www.guidelines.co.uk/musculoskeletal-and-joints-/ covid-19-rapid-guideline-rheumatological-autoimmune-inflammatory-and-metabolic-bone-disorders/455277.article. Accessed September 17, 2020 
110 Mikuls TR, Johnson SR, Fraenkel L, et al. American College of Rheumatology Guidance for the management of adult patients with rheumatic disease during the COVID-19 pandemic. Arthritis Rheumatol 2020 (e-pub ahead of print). doi:10.1002/art.41301

111 Recommendations for gynecologic cancer care during the COVID-19 pandemic. J Gynecol Oncol 2020;31(4):e69

112 Ramirez PT, Chiva L, Eriksson AGZ, et al. COVID-19 Global Pandemic: Options for Management of Gynecologic Cancers. Int J Gynecol Cancer 2020;30(5):561-563

113 Elledge CR, Beriwal S, Chargari C, et al. Radiation therapy for gynecologic malignancies during the COVID-19 pandemic: International expert consensus recommendations. Gynecol Oncol 2020;158(2):244-253

114 Bogani G, Casarin J, Pinelli C, et al. Management of patients with ovarian cancer in the COVID-19 era. J Surg Oncol 2020;122(2):122-123

115 India State-Level Disease Burden Initiative Cancer Collaborators. The burden of cancers and their variations across the states of India: the Global Burden of Disease Study 1990-2016. Lancet Oncol 2018;19(10):1289-1306

116 Ferlay J, Colombet M, Soerjomataram I, et al. Estimating the global cancer incidence and mortality in 2018: GLOBOCAN sources and methods. Int J Cancer 2019;144(8):1941-1953

117 Kumar A, Bhagabaty SM, Tripathy JP, Selvaraj K, Purkayastha J, Singh R. Delays in diagnosis and treatment of breast cancer and the pathways of care: a mixed methods study from a tertiary cancer centre in North East India. Asian Pac J Cancer Prev 2019;20(12):3711-3721

118 De Guzman R, Malik M. Dual challenge of cancer and COVID-19: impact on health care and socioeconomic systems in Asia Pacific. JCO Glob Oncol 2020;6:906-912

119 Dietz JR, Moran MS, Isakoff SJ, et al. Recommendations for prioritization, treatment, and triage of breast cancer patients during the COVID-19 pandemic. the COVID-19 pandemic breast cancer consortium. Breast Cancer Res Treat 2020;181(3):487-497

120 de Azambuja E, Trapani D, Loibl S, et al. ESMO management and treatment adapted recommendations in the COVID-19 era: breast cancer. ESMO Open 2020;5(suppl 3):e000793

121 Dowsett M, Ellis MJ, Dixon JM, et al. Evidence-based guidelines for managing patients with primary ER+ HER2- breast cancer deferred from surgery due to the COVID-19 pandemic. NPJ Breast Cancer 2020;6:21

122 van Maaren MC, Bretveld RW, Jobsen JJ, et al. The influence of timing of radiation therapy following breast-conserving surgery on 10-year disease-free survival. Br J Cancer 2017;117(2):179-188

123 Coles CE, Aristei C, Bliss J, et al. International guidelines on radiation therapy for breast cancer during the COVID-19 pandemic. Clin Oncol (R Coll Radiol) 2020;32(5):279-281

124 Correa C, Harris EE, Leonardi MC, et al. Accelerated partial breast irradiation: Executive summary for the update of an ASTRO evidence-based consensus statement. Pract Radiat Oncol 2017;7(2):73-79

125 Agrawal RK, Alhasso A, Barrett-Lee PJ, et al; FAST Trialists group. First results of the randomised UK FAST Trial of radiotherapy hypofractionation for treatment of early breast cancer (CRUKE/04/015). Radiother Oncol 2011;100(1):93-100

126 Murray Brunt A, Haviland JS, Wheatley DA, et al; FASTForward Trial Management Group. Hypofractionated breast radiotherapy for 1 week versus 3 weeks (FAST-Forward): 5 -year efficacy and late normal tissue effects results from a multicentre, non-inferiority, randomised, phase 3 trial. Lancet 2020;395(10237):1613-1626

127 Elghazawy H, Bakkach J, Zaghloul MS, et al. Implementation of breast cancer continuum of care in low- and middle-income countries during the COVID-19 pandemic. Future Oncol 2020; e-pub ahead of print). doi: 10.2217/fon-2020-0574

128 Bushnell C, McCullough LD, Awad IA, et al; American Heart Association Stroke Council Council on Cardiovascular and Stroke Nursing Council on Clinical CardiologyCouncil on Epidemiology and Prevention Council for High Blood Pressure Research. Guidelines for the prevention of stroke in women: a statement for healthcare professionals from the American Heart Association/American Stroke Association. Stroke 2014;45(5):1545-1588

129 ABN guidance on the use of disease-modifying therapies in multiple sclerosis in response to the threat of a coronavirus epidemic. Available at: https://cdn.ymaws.com/www. theabn.org/resource/collection/6750BAE6-4CBC-4DDBA684-116E03BFE634/ABN_Guidance_on_DMTs_for_MS_and_ COVID19.pdf. Accessed September 17, 2020

130 Qureshi AI, Abd-Allah F, Al-Senani F, et al. Management of acute ischemic stroke in patients with COVID-19 infection: report of an international panel. Int J Stroke 2020;15(5):540-554

131 Co CO, Yu JRT, Laxamana LC, David-Ona DIA. Intravenous thrombolysis for stroke in a COVID-19 positive filipino patient, a case report. J Clin Neurosci 2020;77:234-236

132 Barnes GD, Burnett A, Allen A, et al. Thromboembolism and anticoagulant therapy during the COVID-19 pandemic: interim clinical guidance from the anticoagulation forum. J Thromb Thrombolysis 2020;50(1):72-81

133 Sugiyama Y, Tsuchiya T, Tanaka R, et al. Cerebral venous thrombosis in COVID-19-associated coagulopathy: a case report. J Clin Neurosci 2020;79:30-32

134 Lodigiani C, Iapichino G, Carenzo L, et al; Humanitas COVID19 Task Force. Venous and arterial thromboembolic complications in COVID-19 patients admitted to an academic hospital in Milan, Italy. Thromb Res 2020;191:9-14

135 Monitoring and mitigating the secondary impacts of the coronavirus disease (COVID-19) pandemic on WASH services availability and access. , Available at: https://www. unicef.org/documents/monitoring-and-mitigating-secondary-impacts-coronavirus-disease-covid-19-pandemic-wash. Accessed July 30, 2020

136 Gender equity in the health workforce: Analysis of 104 countries. Available at: https://apps.who.int/iris/bitstream/ handle/10665/311314/WHO-HIS-HWF-Gender-WP12019.1-eng.pdf. Accessed July 30, 2020

137 Mitigating the Impacts of COVID-19 on Menstrual Health and Hygiene. Available at: https://www.unicef.org/documents/ mitigating-impacts-covid-19-menstrual-health-and-hygiene. Accessed July 30, 2020

138 Bienvenu AL, Marty AM, Jones MK, Picot S. Systematic review of registered trials of Hydroxychloroquine prophylaxis for COVID-19 health-care workers at the first third of 2020. One Health 2020;10:100141

139 Revised advisory on the use of Hydroxychloroquine (HCQ) as prophylaxis for COVID-19 infections (in suppression of previous advisory dated 23rd March 2020) . Available at: https:// www.icmr.gov.in/pdf/covid/techdoc/V5_Revised_advisory_ on_the_use_of_HCQ_SARS_CoV2_infection.pdf. Accessed August 27, 2020

140 Yusuf, K, Gideon, K. Use of hydroxychloroquine during pregnancy and breastfeeding: an update for the recent coronavirus pandemic (Covid-19). Available at: https:// motheriskinternational.com/use-of-hydroxychloroquineduring-pregnancy-and-breastfeeding-an-update-forthe-recent-coronavirus-pandemic-covid-19/. Accessed July 30, 2020

141 Yamakoshi B, Burgers L, Sagar S, et al. Mitigating the impacts of COVID-19 and menstrual health and hygiene. Available at: https://www.unicef.org/documents/mitigating- 
impacts-covid-19-menstrual-health-and-hygiene. Accessed September 17, 2020

142 World Health Organization and the United Nations Children's Fund, WASH in health care facilities. Available at: https:// apps.who.int/iris/bitstream/handle/10665/311620/97892415 15504-eng.pdf?ua=1. Accessed September 17, 2020

143 Nextstrain: analysis and visualization of pathogen sequence data. Available at: https://nextstrain.org/docs/getting-started/ introduction. Accessed September 17, 2020

144 Hylodynamic analysis of Indian SARS-CoV2 genomes. Available at: https://data.ccmb.res.in/gear19/auspice/. Accessed September 17, 2020

145 Banu S, Jolly B, Mukherjee P, et al. A distinct phylogenetic cluster of Indian SARS-CoV-2 isolates. bioRxiv 2020; doi: $10.1101 / 2020.05 .31 .126136$

146 Bhoyar RC, Jain A, Sehgal P, et al. High throughput detection and genetic epidemiology of SARS-CoV-2 using COVIDSeq next generation sequencing. Genomics 2020; doi: $10.1101 / 2020.08 .10 .242677$

147 Zhang X, Tan Y, Ling Y, et al. Viral and host factors related to the clinical outcome of COVID-19. Nature 2020;583(7816): 437-440

148 Shang J, Ye G, Shi K, et al. Structural basis of receptor recognition by SARS-CoV-2. Nature 2020;581(7807) :221-224

149 Hoffmann M, Kleine-Weber H, Schroeder S, et al. SARS-CoV-2 cell entry depends on ACE2 and TMPRSS2 and is blocked by a clinically proven protease inhibitor. Cell 2020;181(2): 271-280.e8

150 Da Silva JS, Gabriel-Costa D, Wang H, et al. Blunting of cardioprotective actions of estrogen in female rodent heart linked to altered expression of cardiac tissue chymase and ACE2. J Renin Angiotensin Aldosterone Syst 2017;18(3): 1470320317722270

151 Bukowska A, Spiller L, Wolke C, et al. Protective regulation of the ACE2/ACE gene expression by estrogen in human atrial tissue from elderly men. Exp Biol Med (Maywood) 2017;242(14):1412-1423

152 Kadel S, Kovats S. Sex hormones regulate innate immune cells and promote sex differences in respiratory virus infection. Front Immunol 2018;9:1653

153 Song H, Seddighzadeh B, Cooperberg MR, Huang FW. Expression of ACE2, the SARS-CoV-2 receptor, and TMPRSS2 in prostate epithelial cells. Eur Urol 2020;78(2):296-298
154 Clinckemalie L, Spans L, Dubois V, et al. Androgen regulation of the TMPRSS2 gene and the effect of a SNP in an androgen response element. Mol Endocrinol 2013;27(12):2028-2040

155 Lucas JM, Heinlein C, Kim T, et al. The androgen-regulated protease TMPRSS2 activates a proteolytic cascade involving components of the tumor microenvironment and promotes prostate cancer metastasis. Cancer Discov 2014;4(11):1310-1325

156 O’Driscoll DN, De Santi C, McKiernan PJ, McEneaney V, Molloy EJ, Greene CM. Expression of X-linked toll-like receptor 4 signaling genes in female vs. male neonates. Pediatr Res 2017;81(5):831-837

157 Devaux CA, Rolain J-M, Raoult D. ACE2 receptor polymorphism: Susceptibility to SARS-CoV-2, hypertension, multi-organ failure, and COVID-19 disease outcome. J Microbiol Immunol Infect 2020;53(3):425-435

$158 \mathrm{Lu} \mathrm{Z}$, Carter AC, Chang HY. Mechanistic insights in X-chromosome inactivation. Philos Trans R Soc Lond B Biol Sci 2017;372(1733):20160356

159 van der Made CI, Simons A, Schuurs-Hoeijmakers J, et al. Presence of genetic variants among young men with severe COVID-19. JAMA 2020;10.1001/jama.2020.13719

160 BOARD OF GOVERNORS: In supersession of the Medical Council of India. Telemedicine Practice Guidelines: Enabling Registered Medical Practitioners to Provide Healthcare Using Telemedicine. Available at: https://www.mohfw.gov.in/pdf/ Telemedicine.pdf. Accessed September 17, 2020

161 Earl HM, Hiller L, Vallier AL, et al; PERSEPHONE Steering Committee and Trial Investigators. 6 versus 12 months of adjuvant trastuzumab for HER2-positive early breast cancer (PERSEPHONE): 4-year disease-free survival results of a randomised phase3 non-inferiority trial.Lancet2019;393(10191): 2599-2612

162 Powers WJ, Rabinstein AA, Ackerson T, et al; American Heart Association Stroke Council. 2018 guidelines for the early management of patients with acute ischemic stroke: a guideline for healthcare professionals from the American Heart Association/American Stroke Association. Stroke 2018;49(3):e46-e110 